Fauske \& Associates, Inc.

16w070 West 83rd Street

Burr Ridge, Illinois 6052?

(312) $323-8750$

DISCLAIMER

This report wes prepered es an scconsl of work aponered by an agency of the United Sutse Government. Neither the Unitod States Government sor any asency thereof, not any of their employoes, makes any wartanty, express or imptied, or assumes any legal liability or responsibility for the sceuncy, completeneses, of usefulness of uny information, appartos, product, of process disclosed, of represents that its use would not inftinge privately owned rights. Reference berein to any specific commersid product, process, or cetvice by trade atume trademart, manufacturer, or ollervise does pst nesenurily constitute or imply its andorsement, recommendation, of favoring by the linilod States Government or any sgency thereol. The viem and opinions of authors expresed berein do not necessurily uate or reflect those of the United States Govemiment of any seneng thereof.

\title{
SAFETY ANALYSIS OF
}

\section{SISL PROCESS MODULE}

\section{Prepared for:}

\section{Lawrence Livermore National Laboratories}

May, 1983 
Work performed inder the auspices of the U.S. Department of Energy by the Lawrence Livermore Laboratory under contract number W-7405-ENG-48.

This document was prepared as an account of rork sponsored by an agency of the United States Government. Neither the United tates Government nor any agency thereof, nor any of their employees, makes any warranty, expressed or implied, or assume any legal liability or respons 'bility for the accuracy, completeness, or usefulness of any information, apparatus, product, or process disciosed, or represents that its use would not infringe privately owned rights. Reference herein to any specific comercial product, process, or service by trade name, trademark, manufacturer, or otherwise does not necessarily constitute or imply its endorsement, recomendation, or favoring by the United States Government or any agency thereof. The views nd opinions of authors expressed herein do not necessarily state or reflect those of the United States Government or any agency theraof. 
Page No.

SUMHARY $\ldots \ldots \ldots \ldots \ldots \ldots \ldots \ldots \ldots \ldots \ldots$

1.0 intRODUCTION $\ldots \ldots \ldots \ldots \ldots \ldots \ldots \ldots \ldots$

2.0 accident initiatoRs $\ldots \ldots \ldots \ldots \ldots \ldots \ldots \ldots$

2.1 Design Basis Accidents .............. 2

2.2 "Once-in-a-Lifetime" Accident . . . . . . . . . . 6

3.0 BASIC CONSIDERATIONS OF VAPOR EXPLOSIOHS $\ldots \ldots \ldots \ldots$

3.1 introduction $\ldots \ldots \ldots \ldots \ldots \ldots$

3.2 Vapor Explosion Criteria $\ldots \ldots \ldots \ldots$

3.3 Prenixing . . . . . . . . . . . . . 11

3.4 Propagation and Fine-Scale Mixing . . . . . . . . 16

3.5 Vapor Explosion Damage Potential .......... 17

3.6 Surmary . . . . . . . . . . . . . 17

3.7 References .................. 13

4.0 SteaM EXPLOSION EVALUATION $\ldots \ldots \ldots \ldots \ldots$

4.1 Introduction ..................... 20

4.2 Design Basis Accidents . . . . . . . . . . . . 20

4.2 .1 Explosive rield . . . . . . . . . . 21

4.2 .2 Pressure Pulse Evaluation . . . . . . . . 25

4.3 Once-in-a-Lifetime Accident . . . . . . . . . . 29

4.4 References ................... 30

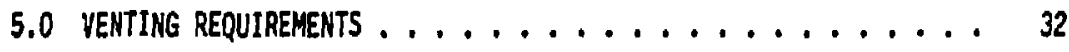

5.1 Design Basis Accidents . . . . . . . . . . . 32 
Page No.

5.2 "Once-in-d-Lifetime" Accident . . . . . . . . . . 32

6.0 THERMAL MELT-THROUGH COHSIDERATIONS $\ldots \ldots \ldots \ldots \ldots$

6.1 Wall Attack by Eutectic Formation . . . . . . . . . . 34

6.2 References $\ldots \ldots \ldots \ldots \ldots$. . . . . . . . 40

7.0 IMPLOSION CONSIDERATIONS . . . . . . . . . . . . 4 I

7.1 Vessei Pressurization . . . . . . . . . . . . . 41

7.2 Entrainment potential of Meit . . . . . . . . . 41

8.0 hYOROGEN FORMATION AMD COMBUSTION $\ldots \ldots \ldots \ldots \ldots$

8.1 Introduction ................... 43

8.2 Bounding Analysis . . . . . . . . . . . . . 43

8.3 References $\ldots \ldots \ldots \ldots \ldots . \ldots \ldots$

9.0 STRUCTURAL CONSIDERATIONS $\ldots \ldots \ldots \ldots \ldots \ldots \ldots$

9.1 Introduction $\ldots \ldots \ldots \ldots \ldots \ldots . \ldots \ldots$

9.2 Material Properties and Design Parameters . . . . . . . 47

9.3 Dynamic Pressure Loading . . . . . . . . . . . 51

9.4 Long Term Vessel Pressurization . . . . . . . . . . 62

9.5 Intemal Missiles . . . . . . . . . . . . . . 62

9.6 Alternative design . . . . . . . . . . . . . 69

9.7 Conclusions . . . . . . . . . . . . . . . . 69

9.8 References $\ldots \ldots \ldots \ldots \ldots$

10.0 conclustons $\ldots \ldots \ldots \ldots \ldots \ldots \ldots \ldots \ldots \ldots \ldots \ldots$ 
1

1

\section{TABLE OF COMTENTS (Continued)}

Page No.

APPENDIX A - Sufficient Molten Material . . . . . . . . 73

APPEMDIX B - Hydrogen Formation from Uranium-Air/Steam Reaction . . . 76 


\section{LIST OF FIGURES}

Figure No.

Page No.

2.1 Overall view of the proposed SISL process module . . . 3

2.2 Iliustration of vessel design and uranium malt crucible................... 4

3.1 Illustration of spontaneous nucieation model ..... 9

3.2 o11 to Freon-22 peak observed pressures ...... 12

3.3 Illustration of the two-stage fragientation and internixing process postulated fcr vapor expicsion .. 13

3.4 Illustration of the prenixing regime and prenixing potentials for different systens........ 15

3.5 Illustration of requirenents for significant work potentlal from a stean explosion .......... 18

4.1 Explosive configuration ............ 22

4.2 Comparison of TKT and point souce explosions .... 27

4.3 Pressure records from test no. 75 showing observed events. [Taken from Ref. 4.5.] ......... 31

$6.1 \quad$ Illustration of the thermal melt-through probien of

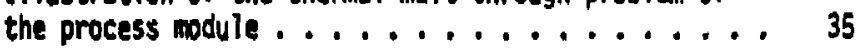

6.2 Comparison of eutectic penetration and thermal

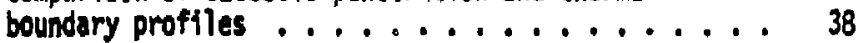

6.3 Iliustration of mode? used to analyze the eutectic meiting attack on the vessel wall ........ 39

8.1 Pressure rises resulting from ignition of hydorgen-air in 12-ft-dianeter sphere at $18^{\circ} \mathrm{C}$. [Taken from Ref.8.1.]............... 44

9.1 SISL Process todule Pod is a self-contained unit . . . 46

9.2 Tenstle strength of grade 2020 graphite ...... 50

9.3 Compressive strength of grade 2020 graphite ..... 50

9.4 Dymanic response of 9 foot dtameter SISL vassel neglecting the initfal compressive stress ..... 54 


\section{LIST OF FIGURES (Continued)}

Figure 10.

Page No,

9.5 Dynamic response of 15 foot diameter SISL tank neglecting the initial compressive stress $\ldots \ldots \ldots 55$

9.6 Response of $9^{\prime}$ diameter vessel to 1600 psi pressure for $0.1 \mathrm{msec} . \ldots \ldots \ldots . \ldots 56$

9.7 - Rasponse of $15^{1}$ diameter vessel to 1600 psi pressure for $0.1 \mathrm{msec} \ldots \ldots \ldots \ldots \ldots . . . \ldots \ldots$

9.8 Process Module Pod end meridfonal stress, $O_{L}$, and hoop stress, $o_{h}$, for 9 foot diameter tank $\ldots \ldots 63$

9.9 Maximum impulse pressure versus graphite shard velocity ................. 65

9.10 Impact of graphite shard on glass port . . . . . . 68

A.1 Thermodynamic path for evaluating the work from a vaportzation process . . . . . . . . . . . . . 74

B.1 Pictorial representation of uranium particle undergoing oxidation .............. 77

B.2 Isothermal reaction rate constants for the uraniumsteam reaction . ................. 80

8.3 Percent oxidation versus temperature for various particle size .................. 84

B.4 Percent reaction versus particle size for various steam concentrations . . . . . . . . . . . . 85

B.5 Hydrogen evolution versus particle size for various steam concentrations . . . . . . . . . . . . 


\section{LIST OF TABLES}

Table No.

Page No.

2.1 Paraneter List for Process Module . . . . . . . 5

2.2 Accident Initiators and Concerns ........ 7

4.1 Livermore Uranium-Water System . . . . . . . 26

6.1 Penetration Rates Above Eutectic Temperature . . . . 36

9.1 Material Properties of 304L Stainless Steel . . . . 48

9.2 Structural Graphite Material Properties ....... 49

9.3 Design Pressure (psig) of SISL Vessel for Various

Dianeters and Thicknesses ........... 52

9.4 Process Pod Elastic Energy Absorption Capability at $70^{\circ} \mathrm{F}\left(21^{\circ} \mathrm{C}\right) \ldots \ldots \ldots$

9.5 Process Pod Total Einergy Absorption Capability at $70^{\circ} \mathrm{F}\left(21^{\circ} \mathrm{C}\right) \ldots \ldots 60$

9.6 Process Pod Maximum Uniform Hoop Strain to Absorb $450 \mathrm{~kJ} \ldots \ldots \ldots 1$

A.1 Initial and Final Pressure $=0.1 \mathrm{MPa} \ldots \ldots$ 


\section{SUMARY}

This report provides an assessment of various postulated accidental occurrences within an experimental process module which is part of a Special Isotope Separation Laboratory (SISL) currently under construction at the Lawrence Liverinore National Laboratory (LLML). The process module will contain large amounts of molten uranium and various water-cooled structures within a vacuum vessel. Special emphasis is therefore given to potential accidental interactions of molten uranium with water leading to explosive and/or rapid steam formatten, as well as uranium oxidation and the potential for combustion. Considerations are also given to the potential for vessel melt-through. Evaluations inelude mechanical and thermal interactions and design implications both in terms of "design basis" as well as "once-in-alifetime" accident scenarios. These scenarios include both single- and multiple-failure modes leading to various contact modes and locations within the process module for possible thermal interactions. The evaluations can be summarized as follows:

- The steam explosion potential for design basis accidents is assessed to be very low. The presence of saturated water and high temperature molten metal in the low pressure environment represent a non-explosiye system.

- The potential of a steam explosion for "once-in-a-lifetime" accident appears higher due to the possibility of subcooled water being avaflable in connection with reaching atmospheric pressure conditions within the process module. However, the efficiency of such explosions is assessed to be very low.

- For safety evaluation purposes, a conservative evaluation of the steam explosion potential is adopted. Nevertheless, the resulting dynamic loads impinging upon the process module pod shell will not plastically deform it. 
- The oxidation and combustion potential in conjunction with such postulated steam-explosion occurrences is not considered significant.

- The possible shrapnel production by the postulated steam explosion is insufficient to cause penetration of the vacuum vessel walls and diagnostic port windows.

- Conservative estimates of longer-term pressurization due to coolant yaporization can be accommodated by controlled venting.

- Thermal melt-through of the pod shell due to an initial attack by low-temperature eutectic formation is considered very unlikely.

In sumary, a vacuum vessel design based upon nominal operatirig conditions would appear sufficient to meet safety requirenents in connection with both "design basis" as well as "once-in-a-lifetime" accidents. Controlled yenting requirements for removal of steam and hydrogen in order to avoid possible long term pressurization events are recomended. Depending upon the resulting accident conditions, the vacuun system (i.e., the roughing system) cocidd also serve this purpose. Finally, based upon accident evaluations of this study, immediate shut-off of all coolant water following an incident Teak is not recormended, as such action may have adverse effects in terms of cool-down requirements for the melt crucibles etc. These requiremients have not been assessed as part of this study. 


\subsection{INTRODUCTIOH}

In order to proceed with a final process module design in connection with the Special Isotope Separation Laboratory (SISL), implications of potentfal accidental occurrences within the process module are presented in this report. Specific considerations relate to potential accidental interactions of moiten uranium metal and water leading to explosive and/or rapid steam production, as well as uranium oxidation and the potential for combustion. Considerations are also given to the potential for vessel melt-through. Consequences of such mechanical and thermal interactions and design implications both in terms of "design basis" as well as "once-in-a-7ffetime" accident scenarios are included.

Definition of potential acident initiators in terms of "design basis" and "once-in-d-1ffetime" scenarios are summarized in Section 2. Basic considerations including general requirements for a damaging stean explosion are discussed in Section 3. Conservativa assessments of the steam explosion potential in terms of structural implications as well as ?ess rapid steam production in terms of venting requirements are presented ir. Sections 4 and 8 , respectively. Section 6 provides an assessment of the prccess vessel meitthrough potential and considerations of vessel implosion are discussed in Section 7. The potential for hydrogen fomation and combustion is developed in Section 8 and detailed structural considerations in connection with hypothetical steam explosion occurrences are presented in Section 9. A sumary of the overall evaluation including recommended design and operating practices is given in Section 10. 


\subsection{ACCIDENT INITIATORS}

A number of accident scenarios can be postulated that may rasult in various forms of contact batween the molten uranium metal and coolant water within the process module (see Figs. 2.1 and 2.2).* The likelihood and severity of such accident scenarios are discussed below in tems of "design basis" and "once-in-a-1ffetime" accidents. In addition to the steam explosion potential, considerations include slower vapor produstion moies and corresponding venting requitrements, the potential for metal oxidation and combustion as well as the potential for vesse] melt-through.

\subsection{Design Basis Accidents}

Design basts accidents include single fallure modes. A steam explosion potential can arise due to either surn through of the bottom of the crucible (see Fig. 2.2), resulting in water injected from below into the uranium meit or burn through from above resulting in water injected unto the melt surface. In either case low pressure saturated water conditions would be involved because of the inherant high vacuum operation of the process module. The implication of this condition relative to the vapor explosion patential is discussed in Section 3, and a conservative estimate of the explosion potential covering boin contact modes is addressed in Section 4 . Corresponding structural impicications are developed in Section 9.

In the absence of steam explosion, the potential still exists for rapid vaporization in the case of coolant line break. Such an exit is considered in section 5 to establish design basis requirements in terms of venting.

Finally, the consequences associated with vessel implosion due to a window rupture including uranium metal entraiment, oxidation and combustion are considered in section 7.

*A parameter list is provided in Table 2.1 including various dimensions of the process module pod, uranium metal crucible, various internal components and anticingted initial conditions. 
Pod Conceptuel Design

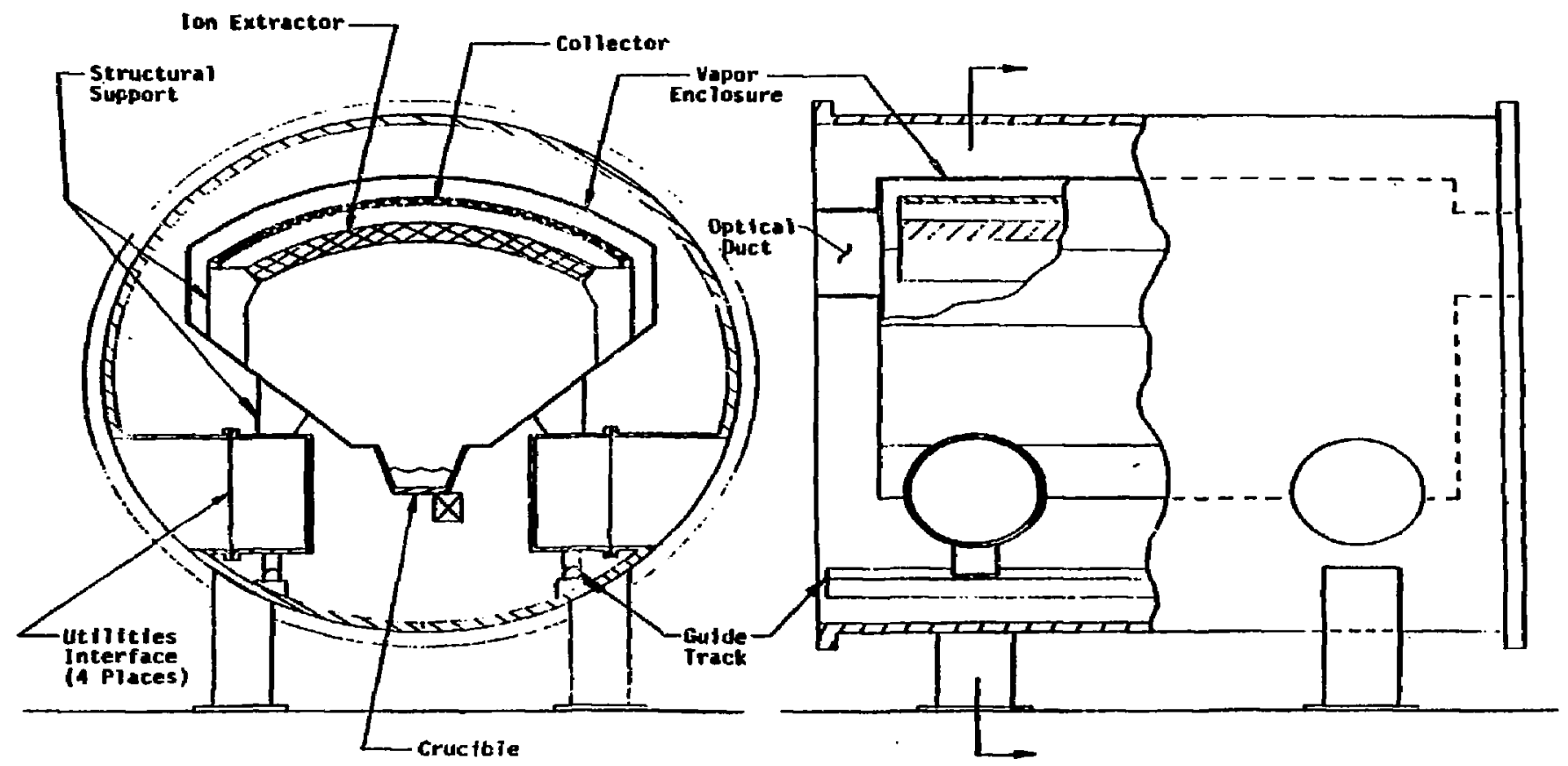

Fig. 2.3 Overall view of the proposad SISL process module. 
I

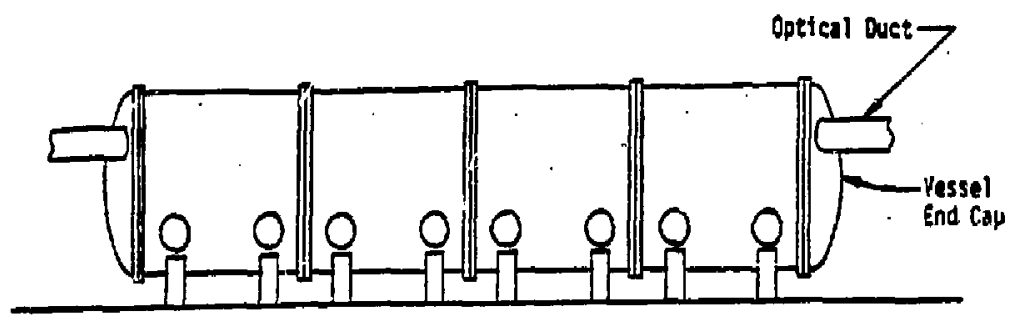

Procass Module (Using 4 Pods)

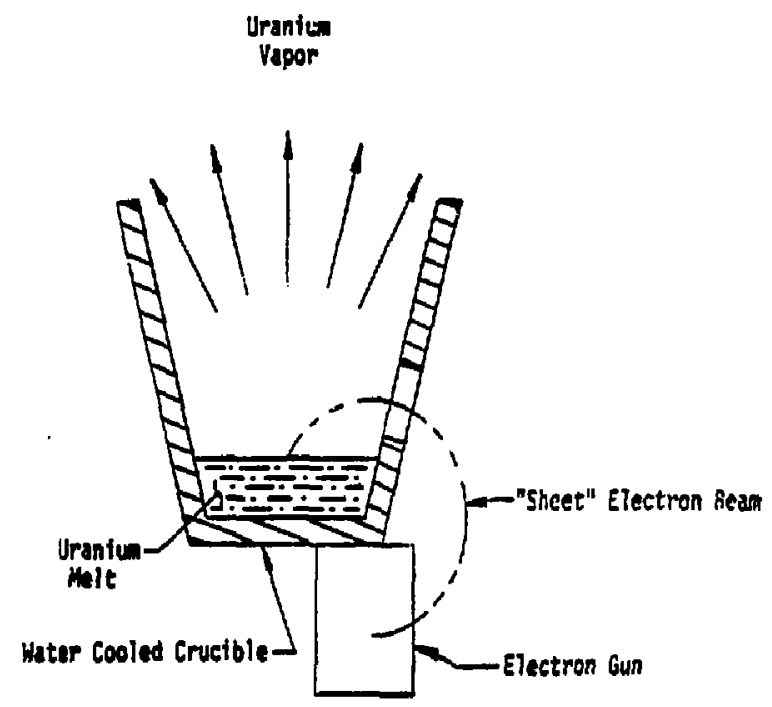

Erucible

Fig. 2.2 Illustration of vessel design and uranium melt crucible. 
Table 2.1

PARAMETER LIST FOR PROCESS MODULE

Process Module and Pod:

- Number of pods per moduie

$1 \cdot 6$

- Pod diameter

$9-15$ feet

- Pod length

9 feet (nominal)

Crucible:

- Individual crucible ?ength

1 or 2 maters

- Total active length per pod

2 meters

- Uranium melt cross-section

$50-250 \mathrm{~cm}^{2}$

- Uranium melt surface area per meter

$1000-2000 \mathrm{~cm}^{2}$

- Power input per meter

$0.5-2 \mathrm{w}$

Initial Conditions:

- Uranium melt temperature

$1500-2500^{\circ} \mathrm{C}$

- Cooling water temperature

$10=40^{\circ} \mathrm{C}$

- Water flow rate (any singie cooling circuit)

$15 \mathrm{gpm}$ (maximum)

- Cooling water pressure

$75-100 \mathrm{psi}$

- Vacuum vessel internal pressure $10^{-6}-10^{-8}$ torr

Internal Components - Graphite

- Volume per pod

$0.37 \mathrm{~m}^{3}$

- Typical thicknesses

$1 \cdot 3 \mathrm{~cm}$

- Typical temperature

$700-1200^{\circ} \mathrm{C}$

Internal Components - Steel Supporting Structure

- Volume per pod

$0.037 \mathrm{~m}^{3}$

- Typical thicknesses

$0.3-1.0 \mathrm{~cm}$

- Typical temperatures

$25-200^{\circ} \mathrm{C}$ 


\section{2 "Once-in-d-Lifetime" Accident}

A "once-in-a-lifetime" accident involves multiple faitures and requires condsiderations of the explosion potential and the process vessel melt-through potential. Again rapid and longer term pressurization events are of interest.

A "once-in-a-lifetime" accident invoiving steant explosion potential includes water accumilation in the bottom of the pod, tive simultaneous failure of a window (double fatlure) resulting in the pressurization of the process vessel and the presence of subcooled watert and catastrophic crucible rupture (third fallure). The pressure source in this case is located imediately adjacent to the vessel wall as compared to a centrally located source term (i.e. crucible location), in the case of the design basis accidents. Implications of these arcident conditions are discussed in Sections 4 and 9.

Venting requirements for "once-in-a-iffetime" accicents are discussed in Section 5 and includes consideration of simultaneous ialiures of the coolant system (i.e. accumulation of water on the botton of the pod) and crucible with subsequent quenching of the uranium metal.

Finally, the melt-through potential of the vessel wall is considered in conjunction with a catastrophic failure of the crucible. The analysis is reported in Section 6 and include consideration of the low temperature eutectic formed upon contact between molten uranium and the vessel wall material.

A sumary of accident initiators and concerns is given in Table 2.2.

*As discussed in Section 3, in the absence of subcooled water, experience indicates that the steam explosion potential becomes vanishingly small. 
Table 2.2

ACCIDENT IHITIATORS AND CONCERNS

Coolant Line Failure

Crucible Fallure

Steam Explosion Potential:

- Within Crucible - Design Basis Accident

- Bottom of Pod - Once-in-a-Lifetime Accident

Thermal Melthrough:

- Bottom of Pod - Once-in-a-Lifetime Accident

Venting Considerations:

- Coolant LIne Fatlure - Design Basis Accident

- Quenching of Uranium - Once-in-a-lifetime Accident

Implosion Faflure

Uranium Oxidation and Combustion Potential - Design Basis Accident Combined Sćeam Explosion - Combustion Potential-Once-in-a-Lifetime Accident 


\subsection{BASIC COHSIOERATIONS OF VAPUR EXPLOSIOHS}

\subsection{Introduction}

Vapor explosions are generally limited to liquid-liquid systems, in which a hot non-yolatile liquid (such as molten uranium metal) is brought into contact with a colder volatile liquid (such as coolant water). A necessary feature is the rapid production of new interfactal area (usually referred to as fragiantation and intermixingl, which is necessary to obtain efficient energy transfer on a time scale consistent with explosive behavior. If the vaporization is rapid enough to produce shock waves, the phenomenon is generalIy termed a vapor explosion. The terms "physical explosion" and "thermal explosion" have also been used. It is thus distinguished from a chemical explosion, in which the energy release stens from chentical reactions. It is possible of course, to have explosions in which both physical vapor production and chemical reactions contribute, such as in mixing of high temperature molten uranium with water. The latter potential for hydrogen formation is discussed separately in section 8.

\subsection{Vapor Explosion Criteria}

The necessary fragmentation and intermixing feature of vapor explosion requires that the interface temperature $\left\langle T_{j}\right\rangle$ upon contact between the hot and cold llquids exceeds the "spontaneous" nucleation temperature $\left(T_{s n}\right)$ of the volatile liquid [3.1], The concept is illustrated in Fig. 3.1. $T_{f}$ is given by

$$
T_{1}=\frac{a_{h} T_{h}+a_{c} T_{c}}{a_{h}+a_{c}}
$$

where subscripts $h$ and $c$ refer to the hot and cold liquids respectively, a - $\sqrt{k_{p C}}$ and $k$ is the thermal conductivity, $\rho$ is the density and $c$ is the specific heat.

Spontaneous nucleation is the process whereby in a liquid bubbles form against the pressure from the surface tension, without external 

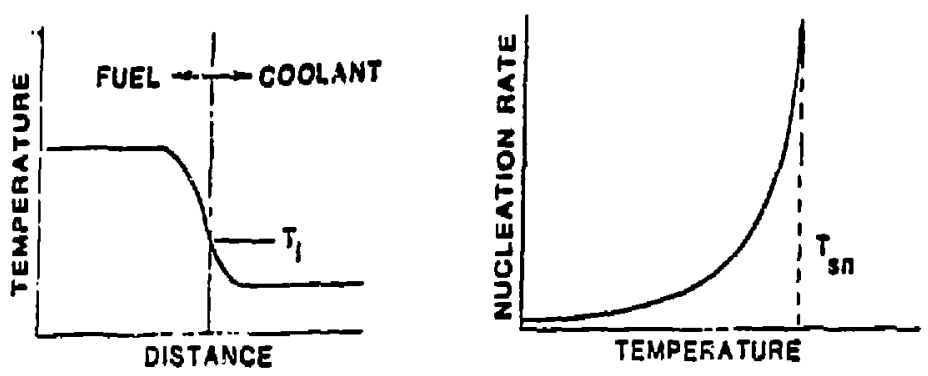

\section{EXPLOSION CRITEAION}
(a)
$T_{1}>T_{\text {sn }}$
(b)

Fig. 3.1 illustration of spontanec'ss nucleation model. 
nucleation sites. The energy to form spherical vapor bubble of radius $r$ with surface tension o is given by $W=4 \pi r^{2} \sigma+4 / 3 \pi r^{3}\left[P_{l}-P_{v}\right.$ ] (where $P_{l}$ and $P_{Y}$ are pressures in the liquid and vapor, respectively) and at the limit of stability $P_{l}-P_{V}=-2 \sigma / r$ so that, neglecting $P_{l}$

$$
w=\frac{16 \pi 0^{3}}{3 p_{v}^{2}}
$$

The rate oi nucleation becomes $J=A(T) \cdot \exp (-W f(\theta) / k T$, where $f(\theta)$ is a functional relationship involving the contact angle $\theta^{*}$ and is included to account for the possiblitity of spontaneous nucleation at the liquid-liquid interface rather than in the bulk of the volatile fluid thomogeneous nucleation). The exponential doninates this equation, so that rapid nucleation occurs when

$$
\frac{16 n 0^{3}}{3 P_{v}^{2}} f(\theta)<k T_{s}
$$

and the temperature of spontaneous nucieation is approximately

$$
T_{s}=\frac{1680^{3}}{3 P_{v}^{2} k} f(\theta)
$$

At this temperature, the exponential is a very strong function of temperature, causing the nucleation rate, i.e. number of bubbles formed per unit volume and time, to increase many orders of magnitude par ${ }^{\circ} \mathrm{C}$. The large scale vapor explosion criterion therefore, becomes

\footnotetext{
*o depends on the watting charcetertstics of a givan system. As show in Ref. [3.1], the spontaneous nucleation threshold is dependent on both contact mode and contact time, and these effects can be represented by specifying the contact angle $a$. In case of perfect wetting $(\theta=0$ which corresponds to $f(\theta)$ *1), the Iimit of superhat (homogeneous nucleation) is attained.
} 


$$
\begin{array}{ll}
T_{1}>T_{s} & \text { explosions are possible } \\
T_{i}<T_{s} & \text { explosions are impossible* }
\end{array}
$$

The evidence for this requirement is very persuasive, running from tests with single drops through a large number of pouring and mixing experiments in the kg range with many different liquids exploding at a precise temperature (Fig. 3.2 shows the onset of explosive interaction for the saturated Freon 22-0il system when $T_{1}$ exceeds $T_{s n}$ ). None has yet been observed experimentally that violates the criterion [3,3].

Application of the vapor explosion criterion to the molten ursnium metal-water system clearly shows that the potential for such an explosion exist, i.e. $T_{i}$ is substantialty above the spontaneous nucleation temperature (approximately $305^{\circ} \mathrm{C}$ ) as well as the thermodynamic critical temperature for water. Kowever, it should be emphasized that this criterion only supplies necessary and not sufficient conditions for a large scale explosion. As such it is necessary to mechanistically address the fragmentation and intermixing process. Generally speaking this process has been postulated to take place in two stages inciuding a relatively slow premixing phase involving fragmentation and intermixing on a coarse scale (of the order of $1 \mathrm{~cm}$ ) in the f1lm bolling mode, and a subsequent very rapid high pressure liquid-liquid fine-scale fragmentation and intermixing (sub inl scale) in connection with the propagation stage [3.2], (see Fig. 3.3). Some basic considerations are provided below relative to the intermixing potential for the uranium-water system.

\subsection{Premixing}

To a first order, intermixing would appear possible if the vapor flux in the nucleation 11 mited film boiling regime $\left(T_{f}>T_{s}\right)$ is well below

"It should be noted that small scale superneat limiting explosions are possible for $T_{f}<T_{\text {s }}$ as long as the hot liguid bulk temperature exceeds or equals T. T.e. following liquid-liquid contact and a brief waiting period a thin layer of the more volatile material can be heated to $T$. In fact, explosive yapor growth which results upon exceeding $T$ localis can also serve as a trigger for a progagating vapor explosion Shere the bulk of the system has experienced pre-mixing as a result of $T_{i}>T_{5}$. 
$.12-$

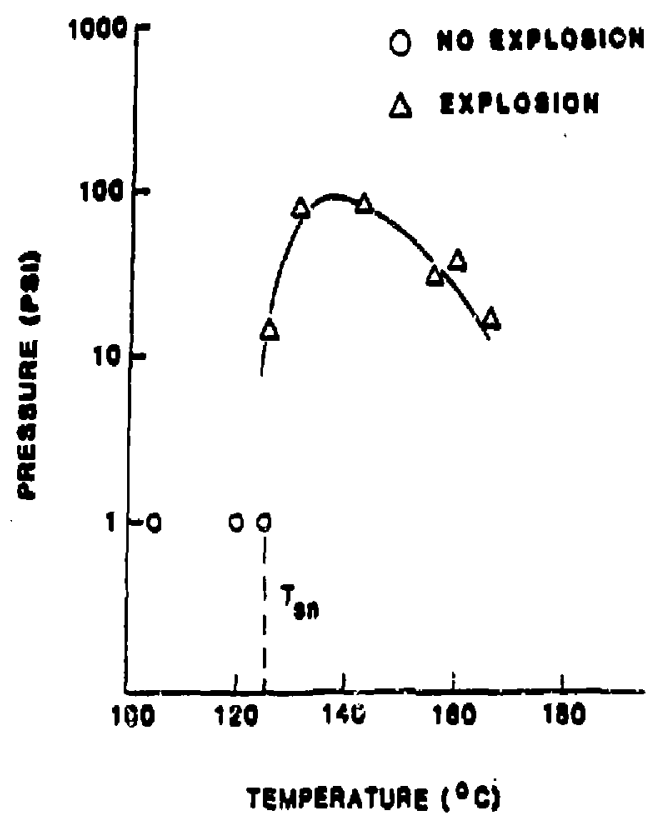

Fig. 3.2 ofl to Freon-22 peak observed pressures [3.2]. 


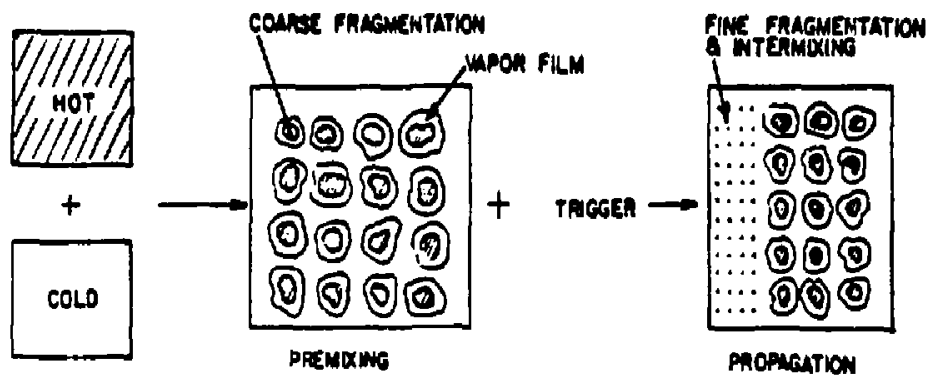

Fig. 3.3 Illustration of the tim-stage fragmentation and intermixing process postulated for yapor explosion. 
the hydrodynamically limited critical heat flux value (see fig, 3.4). The latter value is generally interpreted to be reached when the vapor flux exceeds the fluidization velocity [3.4], i.e. If this vapor flux can be maintained, the volatile liquid will rema in physically separated from the not surface (in this case the hot liquid) ruling out significant intermixing.

The critical heat flux can be expressed by the well-known Kutateladze equation

$$
q=0.14 h_{f g} \sqrt{g_{g}} \sqrt[4]{g \sigma\left(o_{l}-g_{g}\right)}
$$

where $h_{f g}$ is the latent heat of vaporization, $\sigma$ is the liquid surface tension and $\mathrm{p}_{l}$ and $\mathrm{p}_{g}$ are the liquid and vapor densities, respectively. it is of key interest to compere the critical heat flux value witk the film boiling heat flux given by

$$
q=\sigma E\left(T_{h}^{4}-T_{s}^{4}\right)+h\left(T_{h}-T_{s}\right)
$$

Where $\sigma$ is the Stefan-Boltzmann constant, $\varepsilon$ is the emissivity which is usually set equal to unity, $T_{h}$ is the temperature of the hot surface, $T_{s}$ is the saturation temperature of the volatile liquid and $h$ is the free convection heat transfer coefficient.

For some systems (such as Freon-oil) the film botling heat flux is very low (see Fig. 3.4), hence favoring intermixing which is consistent with the experimentally denonstrated high explosivity for such low temperature systems [3.5]. In contrast, for the molten U-saturated $\mathrm{H}_{2} \mathrm{O}$ system, the film boiling vapor flux due to radiation dominated heat transfer can be well above that corresponding to the hydrodynamic crisis limit* (see Fig. 3.4). Subcooled coolant conditions (which are absent for the design basis accidents - see

*At $2500^{\circ} \mathrm{C}$ urantun metal temperature, the film bofling heat flux is $\sim 3000$ $\mathrm{kw} / \mathrm{m}^{2}$ as compared to the critical heat flux value of $1700 \mathrm{w} / \mathrm{m}^{2}$ at 1 bar pressure. The latter value decresses with decreasing pressure as 11lustrated by Eq. 3.6. 


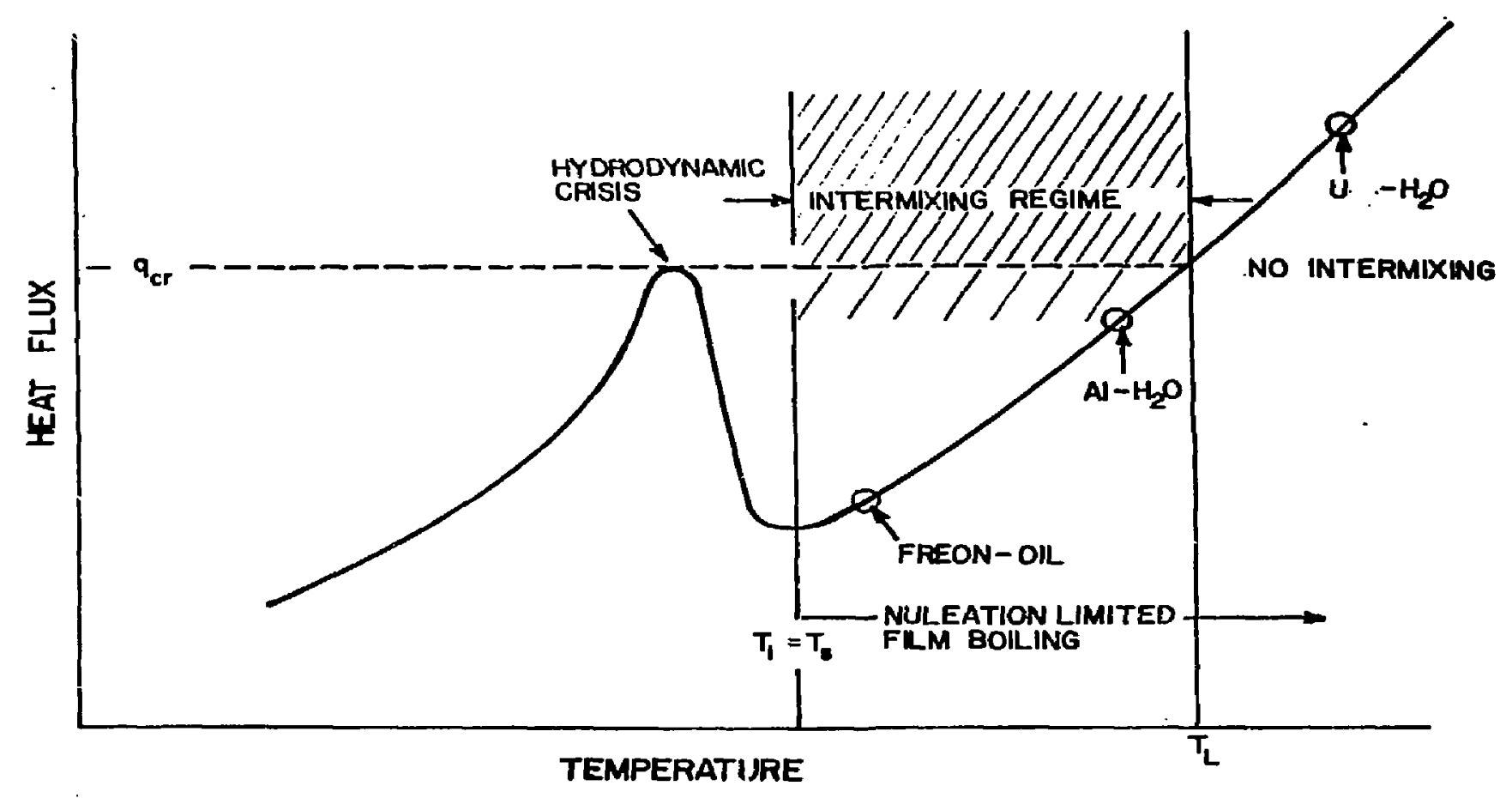

Fig. 3.4 Illustration of the premixing regime and premixing potentials for different systems. 
Section 2) are generally requitred to produce incermixing and explosive interactions for high temperature systems, assuming a sufficient trigger is aval1able. Oniy in the "once-in-a-ilfetime" accident where subcooled water may be present as a result of external pressurization (window rupture) does a potential for intermixing and an explosion occurrence exist. The low efficiency (< a few percent) usuaily observed with Laboratory tests invoiving vapor explosions is discussed further below.

\subsection{Propagation and Fine-Scale Mixing}

For systems which have demonstrated propagating vapor explosions, the corresponding propagation velocity has been observed to be of the orter of $100 \mathrm{~m} / \mathrm{s}$ [3.3]. Since the fragmentation and intermixing velocity cannot exceed the measured propagation velocity, a first order estimate of the time for the postulated fine-scale fragnentation can be obtained from [3.2]

$$
\tau \sim 3 \frac{d}{U} \sqrt{\frac{\rho}{g_{c}}}=3 \frac{0.01}{100} 3 * 10^{-3} \mathrm{~s}
$$

where $d$ is the characteristic dimension resulting from premixing, $U$ is the propagation veloctty and $\rho$ and $\rho_{c}$ is the uranium metal and water density, respectively.

However, for systens which have demonstrated propagating vapor explosions, $T_{i}$ is generally well above the critical temperature, while observed shock pressures are well below the critical pressures [3.5,3.6]. The dynamic impact pressure (oua, where $o$ is the density, is is the velocity and a is the velocity of sound in the liquid) resulting from vapor collapse would therefore appear to be the main pressure source for suppressing the retarding effect due to yaporization during the postulated fine scale fragmentation and intermixing process. The time scale for intermixing becomes there extrenely small and to a first order is given by $d / a$. Required time to avoid evaporative forces is therefore of the order of $(0.01 / 1500) \times 10^{-6} \mathrm{~s}$ which is much smaller than the estimated bresk-up time, $5 q . \quad(3.8)$. It follows that very littie fine scale intermixing can take place. The inability to rapidly 
intermix during the propagation step is consistent with the low energy conversion values (s1\%) noted in vapor explosion experiments carried out to date [3.7].

\subsection{Vapor Explosion Damage Potential}

In contrast to high explosive chemicais, peak transient pressures in a vapor explosion are limited to at most hundreds of atmospheres compared to millions of atmospheres in a TNT explosive. Moreover, pressure pulse rise times for a vapor explosion are of the order of 100 times longer than rise times for shock waves caused by high explosives. The severe damage caused by chemical explosives derives principally from the energy assoctated with the shock wave itself, while for a vapor explosion most of the energy which has the potential to produce damage results from the expanding yapor and not the shock wave. Thus for a vapor explosion to have a significant damage potential in connection with postulated accident scenarios in the process module, the generated vapor must be contained and directed, i.e. the presence of a coherent liquid slug is required in addition to satisfying all the requirements of a large scale explosion, (see Fig. 3.5). Such a configuration is not present in the process module.

\subsection{Sumary}

While the molten uranium metal-water systen satisfies the wellestablished vapor explosion criteria $\left(T_{i}>T_{s}\right)$, premixing conditions are not satisfied for the design basis accidents because of absence of subcooled water. Only in the "once-in-a-lifetime" accident can subconled water be postulated to be available and hence the potentlal for premixing and trigger may exist, but the resultant explosion can be demonstrated to be very weak, because of the inability to sustain significant fine scale fragmentation during the propagation step. However, for the purposes of design evaiuations conservative approach to the steam explosion potential within the process module is presented in the following section. The deveioped source terms are subsequently used in Section 9 to assess structural implications. 


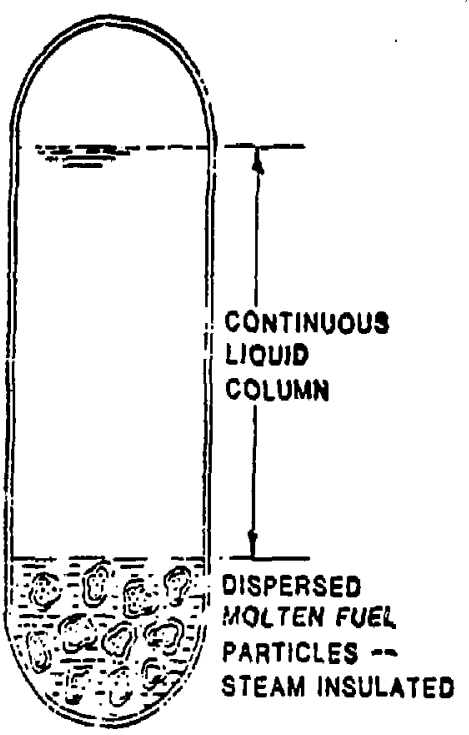

Fig. 3.5 Illustration of requirements for significant work potential from a steam explosion. 


\subsection{References}

3.1 H. K. Fauske, "Some Aspects of Liquid-Liquid Heat Transfer and Explostve Botling," Proc. Fast Reactor Safety Mtg., Beverly Hills, CA, April 2-4, 1974.

3.2 S. J. Board and R. W. Hall, "Recent Advances in Understanding Large Scale Vapor Explosions," Proc. 3rd Specialist Mt 7 . on Sodium/Fuel Interaction in Fast Reactors, PNC N251 76-12, Yo1. 1, Tokyo, Pp. 22-26, March 1976.

3.3 S. G. Bankoff, "Vapor Explosions: A Crittcal Review," Proc. 6th Int'1. Heat Transfer Conf., Vo1. 6, pp. 355-360, 1978.

3.4 S. 5. Kutateladze, "Elements of Hydrodynamics of Gas-Liquid Systems," Fluld Mechanics - Sovtet Research, Vol, 1, 4, p. 29, 1972.

3.5 R. E. Henry, et, al., "Vapor Explosions and Simulant Fluids," "Proc. Int'l. Conf; on Fast Reactor Safety and Related Physics, Chicago, Ih, CONf-76100T, p. 1862, October 1976.

3.6 R. E. Henry and H. K. Fauske, "Nucleation Processes in Large Scale Vapor Expiasions," Trans. ASME, J, of heat Transfer, Vol. 107, pp. 280-287, May 1979.

3.7 L. D. Buxton and W. B. Benedick, "Steam Explosion Efficiency Studies," NUREG/CR-0947, SAND-79-1399, November 1979. 


\subsection{STEAM EXPLOSION EYALUATIOH}

4.1 Introduction

As discussed in Section 3, the potential for an energetic steam explosfon occurrence in connection with postulated accidents within the process module is considered to be very small. In the case of design basis accident considerations, which was postulated to lead to water injection underneath the uranium metal pool surface (see Section 2), the water would be saturated and at low pressure. For such conditions, elementary considerations show that the necessary fragmentation and intermixing are very difficult to achieve.

In the case of the "once-in-e-lifetime" accident, where assumed crucible fallure pours melt into accumulated water in the bottom of the pod, the potentials for an energetic steam explosion as well as the damage potential are considered very small because (1) water most likely would be saturated,* (2) sufficient water accumulartiof to produce an explosion (i.e., at least of $10 \mathrm{~cm}$ depth) in a single pod would require minutes suggesting that the likely out-cone would be a slow quenching process of the molten matal if the cooling water is not shut off, and (3) no sfficient energy transfer mechanism such as slug impact exist.

Nevertheless, for design purposes we have conservatively assumed that energetic steam explosion occurrences will take place. Bunding estimates of such explosions in terms of energy releases and pressure puises for use in assessing the structural response of the process module (see Section 9) are discussed below for both design and "once-in-a-iffetime" accident scenartos.

\subsection{Design Basis Accidents}

For the design basis accidents involving coolant line failure resulting in either water injection below or above the metal surface in the

*The presence of subcooled water would require rapld pressurization of the process module by external means (such as a window rupture). 
crucible, the below surface injection mode of contact is selected as the reference case. This mode of contact would represent the larger potentiai for an energetic interaction, in view of the difficulty of penetrating the metal surface from above. The radiation heat flux would exceed the critical heat flux at these low pressures (see discussions in Section 3) and hence would prevent substantigl water accumulation. The energy yield is therefore enveloped by the conservative values developed below for below surface injection. These evaluations include (1) the maximum amount of material involved in a hypothetical interaction within the uranium melter, (2) the mechanical work associated with the explosion, (3) the magnitude of the pressure spike arriving at the pod shell and (4) the shape of arbitrary pressure spikes arriving at the shell boundary.

\subsubsection{Explosive Yield}

As a source term for structural evaluation of possible designs for the pods, we will consider the 1 imiting amounts of molten uranium and water which can be intermixed in the configuration shown in Figure 4.1. Only in this configuration could a strong explosive interaction, like a chemical detonation, have any potential. Other mixture configurations, al though more likely, would result in weak thermal explosions with energy yields well below those calculated for the distribution shown in Figure 4.1. With the entrainment of water drops in the uranium under film boiling conditions, the maximum amount of water can be equated to that required to levitate the surrounding liquid metal, as a result of vapor produced in film boiting. The superficial steam velocity $\left(U_{g}\right)$ necessary to levitate the molten uranium and breakdown the finely dispersed structure is given by:

$$
U_{g}=\frac{0.14 \sqrt[4]{g \sigma\left(\rho_{u}-\rho_{g}\right)}}{\sqrt{\rho_{g}}}
$$

where $g$ is the gravitational acceleration, $O$ is the metal-stean surface tension, and $\rho_{u}$ and $\rho_{g}$ are the uranium and steam densities respectively. 


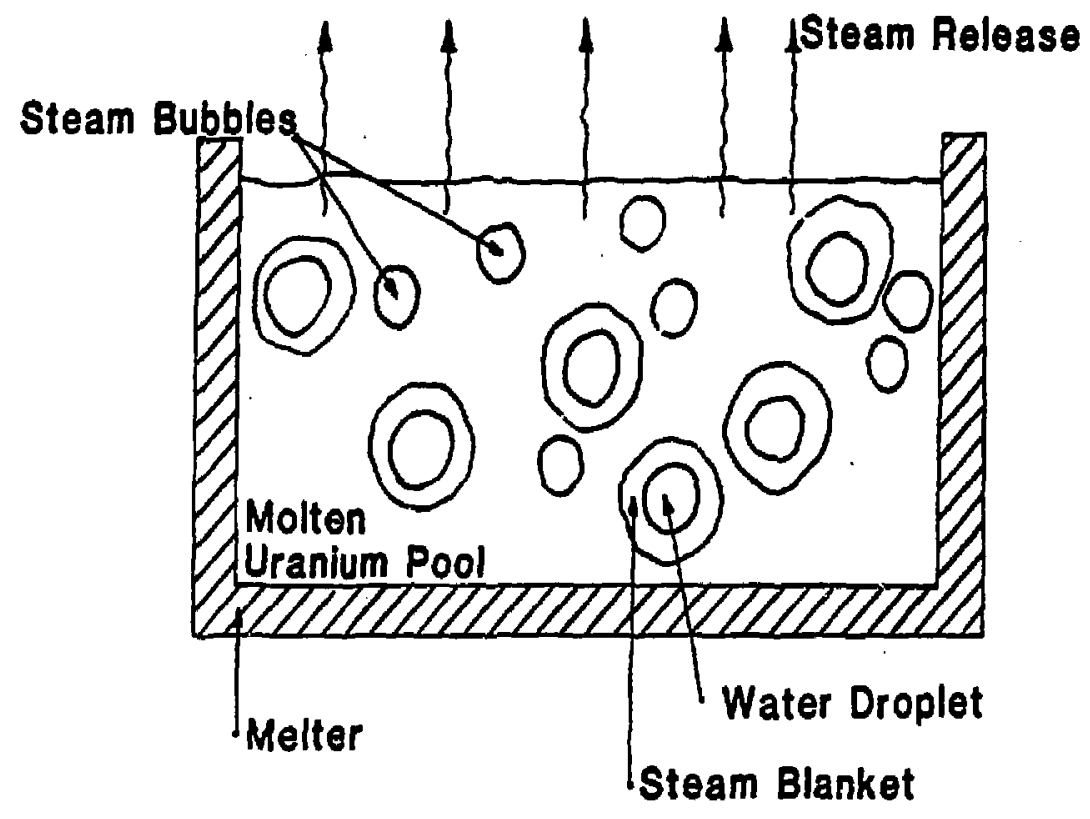

Figure 4.1

EXPLOSIVE CONFIGURATION 
Consider the film boiling heat flux $\left.[q / A)_{F B}\right]$ off the surface of the water droplets as given by

$$
q / A)_{F B}=\sigma\left(T_{F}^{d}-T_{f}^{4}\right)+h\left(T_{F}-T_{f}\right)
$$

The superficial steam velocity can be determined once the number of droplets is calculated. In the above expression, $\sigma$ is the Stefan-Boltzmann constant, $T_{F}$ is the uranium temperature, $T_{f}$ is the saturated water temperature at the system pressure, and $h$ is the heat transfer coefficient for this film boiling configuration $\left(\sim 0.3 \mathrm{kw} / \mathrm{m}^{20} \mathrm{C}\right)$. The total heat flux based upon the pool cross-sectional area corresponding to the steam formec in this $\mathrm{f1} 1 \mathrm{~m}$ boilling configuration is obtained by multiplying the droplet heat flux times the number of droplets (N) and the droplet surface area and dividing by the pool surface area $\left(A_{p}\right)$.

$$
\left.q / A)_{p}=q / A\right)_{F B} \cdot 4 \pi r_{p}^{2} \cdot N / A_{p}
$$

This is then compared to the heat flux associated with the levitation criteria which is obtained by multiplying the levitation veiocity times the steam density $\left(\rho_{g}\right)$ and the latent heat of vaporization $\left(h_{f g}\right)$ at the system pressure.

$$
q / A)_{p}=U_{g} \rho_{g} h_{f g}
$$

Comparing these two heat fluxes, one can calculate the number of dropiets availabie as a function of the droplet radius.

$$
N=\frac{\rho_{g} A_{p} U_{g} h_{f g}}{4 \pi r_{p}^{2}\left[\sigma\left(T_{F}^{4}-T_{f}^{4}\right)+h\left(T_{F}-T_{f}\right)\right]}
$$

For a system in which explosive reactions could be anticipated, the energy available from a given droplet exploding must be sufficient to mix many other droplets in an explosive time scale. The energy required for rapidly mixing 
the liquid-1iquid system can be estimated from the one-step mixing criteria posed by Cho, fauske, and Grolmes [4.1]. In this single step mixing, the materlais are assumed to mix on an equal volume basis and the energy requirement for a given droplet can be spectfied as

$$
E_{m}=3 / 8 \frac{C_{D p_{f}} f^{2}}{t_{m}^{2} r_{1}}
$$

Where $C_{D}$ is the drag coefficient in this dense, equal volume systeri (approximately 20), $V$ is the volume of the droplet being mixed, and $t_{m}$ is the mixing interval. This interval represents the time avallable to rapidly mix the two materials so that an effictent themal interaction could be sustained. for such an interaction, this mixing time must be considerably less than 1 millisecond (from Eq. 3.8), but for the scoping calculations, assuming a one millisecond time scale is sufficient. In general, an efficient thermal interaction can be anticipated to deliver approximately one third of the thermal energy stored within the hot molten material in the form of mechanical work (this is discussed in Appendix A). Using this rule of thumb, and assigning a criteria that for a propagating system the explosion of a single particle should be sufficient to mix many additional particles. For these design evaluations, consider the requirenent to be thirty additional droplets even though a more realistic number would be 100 . Consequently, the values given below are conservative. The energy release from a given yolume of fuel can be equated to the energy required to mix 300 equal volunes of water.

$$
\rho_{F} v c_{F}\left(T_{F}-T_{f}\right)=\frac{300}{8} \frac{c_{D} \rho_{f} v^{2}}{t_{m}^{2} r_{1}}
$$

where $r_{1}$ is the final radius of the mixed particles $~ 100$ um. This expression can be translated to solve for the material volume and thus for the initial radius of the liquid particles.

$$
r_{p}=\left\{\frac{0.02 r_{1}^{2} t_{m} \rho_{F} c_{F}\left(T_{F}-T_{f}\right)}{\pi c_{D} \rho_{f}}\right\}^{1 / 3} .
$$


Assuming the uranium to have a temperature of $2800^{\circ} \mathrm{K}$, the droplet radius calculated is approxinately $0.5 \mathrm{~cm}$, or a droplet diameter of $1 \mathrm{~cm}$. This is in agreement with the general configurations assumed by various models [4.2] which are based upon a configuration like that shown in Figure 4:1. However, these models did not mechanistically determine how this configuration would be developed or calculate the size required for establishing a propagation system.

Using the above numbers in the evaluation for the number of droplets avaliable in a pre-mixed configuration without levitating the surrounding uranium pool are given in Table 4.1. As shown this results in 430 droplets for a configuration which the initial uranium temperature is $2800^{\circ} \mathrm{K}$ and a pressure of $0.1 \mathrm{MPa}$, and 2560 droplets if the temperature is only $1800^{\circ} \mathrm{K}$. The difference between these analyses is the high surface temperature of the uranium metal and the efficient energy transfer process resulting in a large heat flux off the surface of the droplets. For the first case, the mass of water contained in the uranium water pool is 0.173 kilograms and in the second case 0.604 kilograms. Using the analysis presented in Appendix $A$ for an efficient thermal interaction, which delivers approximately $1,000 \mathrm{~kJ} / \mathrm{kg}$ of water, the former results in a work potential of $173 \mathrm{~kJ}$ where as the latter delivers $604 \mathrm{~kJ}$ of work to the surroundings.

\subsubsection{Pressure Pulse Evaluation}

Experiments have demonstrated that very strong shock waves in the near vicinity of the source decay as one over the radius cubed, strong shock waves in the range from 2 up to 10 dimensional radii decay as $1 / r^{2}$ and those weaker shock waves in the later portions of the expansion decay as $1 / r$. This is illustrated in Fig. 4.2 for TNT explosions, and while these are much stronger than steam explosions in terms of their pressure rise time and propagation characteristics, they can be conservatively used to represent the steam explosion behavior for design purposes. Considering the expansion to occur as $1 / r^{2}$, is in general sufficient for most evaluations where the maximum stress is of interest. Extensive experiments [4.3, 4.4] for various vapor explosion systems have show that the maximum pressure exhibited during the major expansion of the fluid is typically half the critical pressure for 
Table 4.1

LIVERMORE URANIUM-WATER SYSTEM

\begin{tabular}{|c|c|c|c|c|c|c|c|c|}
\hline Case & $\begin{array}{l}\text { System } \\
\text { Pressure } \\
\text { MPa }\end{array}$ & Tugan. & $\underset{\substack{\text { Pool Surface } \\
\mathbf{m}^{\mathbf{2}}}}{\text { Poce }}$ & $\begin{array}{c}\text { Superficial Steam } \\
\text { Velocity } \\
\mathrm{m} / \mathrm{s}\end{array}$ & $\underset{m}{r_{n}}$ & Particles & $\begin{array}{l}\text { Water } \\
\text { Mass } \\
\mathbf{g}\end{array}$ & $\underset{K J}{\text { Work }}$ \\
\hline A & 0.001 & 1500 & 0.1 & 15.8 & 3.97 & 152 & 39.8 & 39.8 \\
\hline B & 0.001 & 1500 & 0.2 & 15.8 & 3.97 & 304 & 79.7 & 79.7 \\
\hline C & 0.1 & 1500 & 0.1 & 1.79 & 3.89 & 1280 & 302 & 302 \\
\hline D & 0.1 & 1500 & 0.2 & 1.79 & 3.89 & 2560 & 604 & 604 \\
\hline $\mathbf{E}$ & 0.001 & 2500 & 0.1 & 15.8 & 4.71 & 27 & 11.8 & 11.8 \\
\hline $\mathbf{F}$ & 0.001 & 2500 & 0.2 & 15.8 & 4.71 & 54 & 23.6 & 23.6 \\
\hline G & 0.1 & 2500 & 0.1 & 1.79 & 4.65 & 215 & 86.7 & 86.7 \\
\hline H & 0.1 & 2500 & 0.2 & 1.79 & 4.65 & 430 & 173 & 173 \\
\hline
\end{tabular}




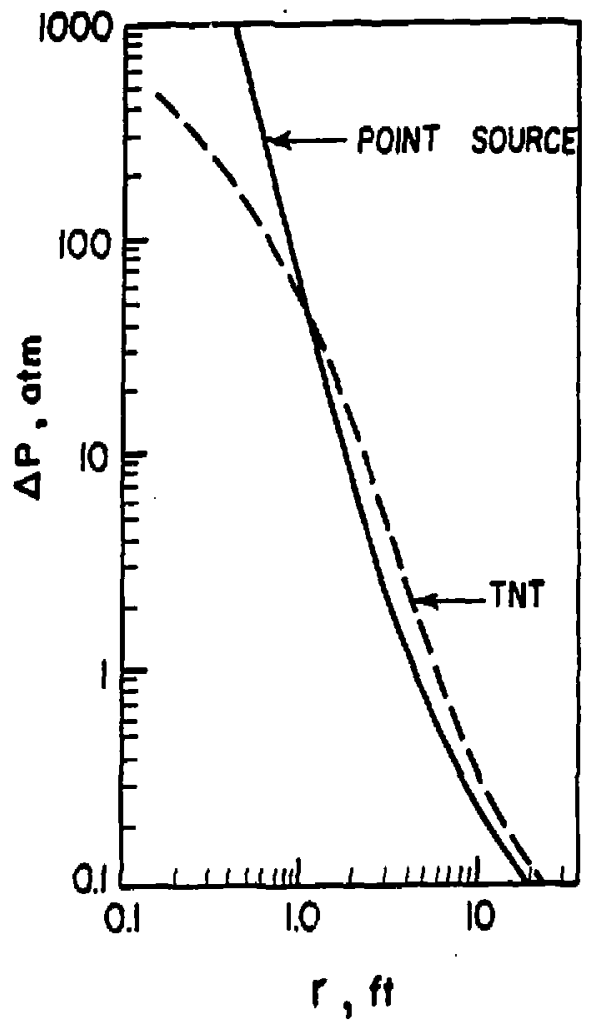

Fig. 4.2 Comparison of TNT and point source explosions. 
the working fluld, I.e., approximately $10 \mathrm{MPa}$ for water. Considering the interaction zone in this uranium-water system to have an initial radius of 0.1 $m$ and a shell radius of $1.5 \mathrm{~m}$ means that the spherical attenuation as the wave grows out to the shell boundary will diminish the original shock wave from 10 $\mathrm{MPa}$ to $0.05 \mathrm{MPa}$ by the time the wave impacts on the boundary. Consequently, this pressure load is well below that required to stress the wall to its elastic ifmit even under steady-state conditions. The latter conditions are summarized in Section 9 for different vacuum vessel designs.

Another method of evaluating the transient loads in a conservative design manner is to estimate the transient loading of the wall with an arbitrary peak pressure but with an energy equal to the mechanteal work yield of the expiosion. Consider the wave to be spherical and propagating at the sonic velocity of air. Thts is an oversimplification of the actual process but will provide for a conventent design tool. The pressure $P$ in the wave can be assumed to be uniform and the wave to have a thickness, $t$, so that the potential energy of the wave, which is equal to the work delivered by the explosion, can be approximated by

$$
W=P V=P 4 \pi r^{2} t
$$

where $P$ is the pressure within the wave, and $A$ is the spherical area. Assuming arbitrary values for the pressure within the wave regardless of that which is realistically assumed from the $1 / r^{2}$ pressure decay, the thickness of the wave can be estimated from the energy requirements.

$$
t=\frac{W}{4 \pi r^{2} p}
$$

With this characteristic thickness and the sonic velocity, the duration of the wave can be estimated from

$$
\theta=t / c
$$

and considering that the reflected pressure is twice the pressure within the wave, this results in a triangular wave pattem with the peak pressure twice 
that within the wave and a total time at the base of the triangular wave of 28. Considering the pressure within the square wave to be $3.1 \mathrm{MPa}$ results in a peak pressure of $6.2 \mathrm{MPa}$ and a total width at the base of the triangular pressure spike of 30 microseconds when the wave impinges upon the shell which is assumed to have a radius of $1.5 \mathrm{~m}$. These conservative evaluations are used as arbitrary source terms for structural evaluations, of the design basis accident in Section 9.

\subsection{Once-in-a-Lifetime Accident}

For the multiple-faflure accident scenario involving coolant line failure in conjunction with a catastrophic crucibie fatiure, the sequence of postulated fallures is of key importance in assessing structural implications to the process module. If the fallures are postulated to occur simultaneously, a relatively large quantity of molten metal would be available to pour onto the bottom of the pod. However, in this case little water would have accuinulated within the vessel and the potential for an energetic steam explosion is negligible. Instead the concern is related to potential thermal attack on the vessel wall and is discussed in Section 6. Accumulation of a significant* quantity of coolant water in the bottom of the pod prior to melt-water contact would require upwards of 2 minutes delay time between a single coolant line failure and catastrophic failure of the crucible. As such, the energy release associated with a hypothetical steam explosion occurrence for such conditions is estimated to be a small fraction of that assessed for the design basis accident, where the coolant water was injected below the melt surface in the crucible.

However, in view of the location of the steam explosion, the dynamic loading seen by the vessel wall in this case would be more severe than in the design basis evaluation. In this context, extensive experiments for various vapor explosion systems have shown that the maximum pressure produced is typically not larger than half the critical pressure for the working fluid,

*In context of having a steam explosion potential a water depth of the order of $10 \mathrm{~cm}$ is considered necessary. 
i.e., approximately $10 \mathrm{MPa}$ for water. Also recognizing that substantial vapor channeling would exist in the shallow water pool at the time of the vapor explosion due to the nesessary pre-mixing process, the shock wave would be severely atter:ated and the effect of the vapor pressure would be dissipated on a time scale correspending to the acoustic relief time of the water pool based upon steam properties. Assuming an effective transmission ?ength of half the initial water depth (1.e., approximately $5 \mathrm{~cm}$ ), the localized pressure source seen by the vessel wall due to an energetic steam explosion is at most sustained for the order of $10^{-4} \mathrm{~s}$. For structural evaluation purposes we wiil therefore assume a square-wave with magnitude of $10 \mathrm{MPa}$ and width corresponding to $10^{-4} \mathrm{s.*}$

\subsection{References}

4.1 D. H. Cho, H. K. Fauske and H. A. Grolmes, "Some Aspects of Mixing in Large-Mass, Energetfo Fuel-Coolant Interactions," preceedings of the International Meeting on Fast Reactor Safety and Related Physics, CONF-761007, V01. 4, Chicago, Illinois, pp. 1852-1861, October 1976.

4.2 S. G. Bankoff, "Vapor Explosions: A Critical Review," Proc. 6th Int'l. Heat Transfer Conf., Vol. 6, pp. 355-360, 1978.

4.3 R. E. Henry, et. al., "Vapor Explosions and Simulant fluids," Proc. Int'i. Conf. on Fast Reactor Safety and Related Physics, Chicago, IL, CONF-761001, P. 1862, October 1976.

4.4 R. E, Henry and H. K. Fauske, "Nucleation Processes in Large Scale Vapor Explosions," Trans. ASME, J. of Heat Transfer, Vol. 10T, pp. 280-287, May 1979.

4.5 C. J. Fry and C. H. Robinson, "Experimental Observations of Propagating Interactions in Metal/Water Systems," Fourth Proc. on FueTCoolant Interactions in Niuclear Reactor Safety, " Bouremouth. United Kingdom, 2-5 April, 1979.

*The highly conservative nature of this source term is illustrated by experimental measurements of molten aluminum- $\mathrm{H}_{2} \mathrm{O}$ explosions pressures in shallow pools [4.5]. As seen in Fig. 4.3, peak pressure events are limited to about $1 \mathrm{HPa}$ and are of extremely short duration. 


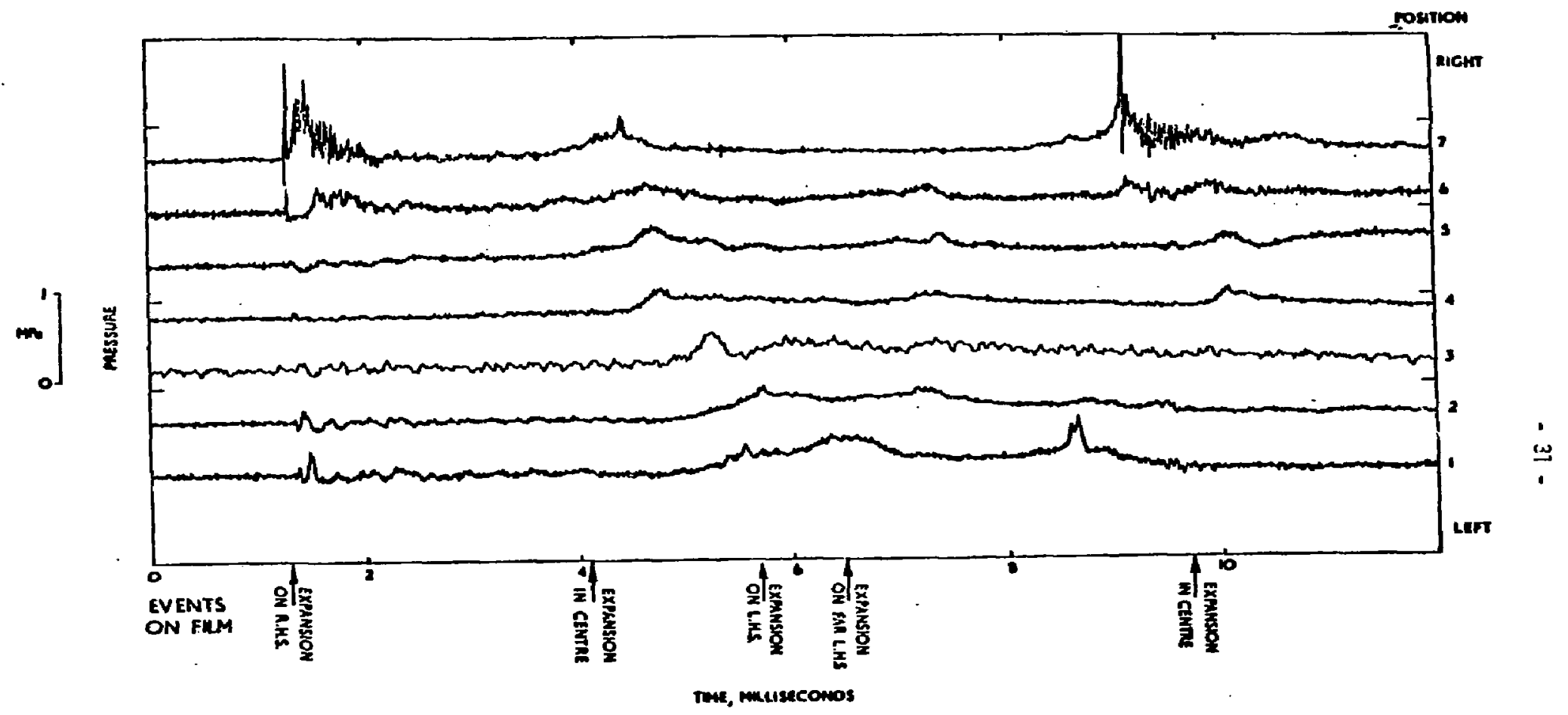

Fig. 4.3 Pressure records from test no. 75 showing observed events. [Taken from Ref. 4.5.] 


\subsection{VENTIHG REQUTREMENTS}

While the potential for steam expiosion in connection with postulated single- as well as multiple-fatlure accidents is considered to be very small, slower rates of evaporization as a result of the hot environment within the process moduie must be anticipated. Venting requirements based upon conservacive estimates of the rates of coolant vaporization in connection with both design basis and "once-in-a-lifetime" accidents are addressed below,

\subsection{Design Basis Accidents}

for the design basis accidene a single coolant line failure (15 GPM) is postulated to occur. For the purpose of bounding the rate of vaporization, the coolant water is assumed to turn into steam as fast as it enters the process module enviroriment.

Assuming vent initiation at 3 bars pressure, a vent diameter of approximately $0.05 \mathrm{~m}$ is sufficient to prevent further pressurization. The flow through the relief device is based upon sonic flow conditions.

\section{2 "Once-in-d-Lifetime" Accident}

In this case the water is postulated to collect at the bottom of the process vessel. A multiple failure situation involving failure of the crucible resu?ts in molten uranium metal falling into the water pool. A steam explosion under these conditions is considered highly unilikely (see Section 4). However, as the molten metal is quenched by the water, a considerable amount of stean will be produced. Again, the actual steaming rate can be bounded by considering the rate that corresponds to the maximum flooding conditions. If this rate is exceeded, the water will be kept away from the hot metal debris and hence slow down the quenching process. To a first order this condition can be estimated from the pool boiling critical heat flux condition $19 " 1700$ $\mathrm{kw} / \mathrm{m}^{2}$ )

$$
q=h_{f g} p_{g}^{1 / 2}\left[\sigma\left(p_{\ell}-p_{g}\right) g\right]^{1 / 4}
$$


where $h_{f g}$ is the latent heat of vaporization, $\sigma$ is the surface tension, $g$ is the gravitational constant, and $\mathrm{P}_{\mathrm{f}}$ and $\mathrm{P}_{g}$ are the liquid and vapor density, respectively.

The maximum rate of coolant vaporization is then obtained from

$$
W=\frac{q \cdot A}{h_{f g}}
$$

where $A$ is concervatively set equal to the water pool surface area. Assuming a single coolant line fallure persists for 2 minutes, a maximum pool surface area of $1.4 \mathrm{~m}^{2}$ is created (which corresponds to a maximum water depth of approximately $10 \mathrm{~cm}$ ). For these conditions a maxinum vaporization rate of 1.1 $\mathrm{kg} / \mathrm{s}$ is obtained. This leads to a vent diameter requitement of approximately $0.05 \mathrm{~m}$ assuming vent initiation at 3 bars prissure. 


\subsection{THERMAL MELT-THROUGH COMSIDERATIONS}

following a postulated catastrophic crucible fallure, the moiten uranium metal is assumed to come into direct contact with the vessel wall as illustrated in Fig. 6.1. Assuming all of the uranium metal content in the crucible ends up on the bottom of the pod, the maximum depth of the uranium pool is approximately equal to the vessel wall thickness ( 0.75 inches) for a 12-ft diameter vessel. Of principle concern here is the potential for vessel wall attack due to formation of a low temperature eutectic between uranium and steel.

\subsection{Mall Attack by Eutectic Formation}

Assuming uranium metai at a maximum temperature of $2500^{\circ} \mathrm{C}$ is coming into direct contact with the vessel wall at a temperature of $100^{\circ} \mathrm{C}$, resuits in an instantaneous contact temperature of $\approx 1300^{\circ} \mathrm{C}$. This temperature is calculated from

$$
T_{i}=\frac{a_{u} T_{u}+a_{5} T_{5}}{a_{u}+a_{5}} \leadsto \frac{T_{u}+T_{5}}{2}
$$

where $\alpha=\sqrt{\text { okc }}$ and $T$ is the temperature, $\rho$ is the density, $k$ is the therma] conductivity and $c$ is the specific heat, and subscripts $s$ and $u$ stands for steel and uranium, respectively. It is noted that $T_{i}$ is less than the yessel wall meiting temperature $\left(21400^{\circ} \mathrm{C}\right)$, but substantially above the eutectic temperature for the uranium metal-steel system $\left(n 800^{\circ} \mathrm{C}\right)[6.1]$. Best estimate penetration rates above the eutectic temperature is listed in Table 6.1.

of particular interest is the rapid increase in the penetration rate when the contact temperature $T_{f}$ is above the uranium metal meiting teaperature $\left(w 1150^{\circ} \mathrm{C}\right)$. As long as this condition is maintained, the penetration rate can be bounded by about 10 mils/s. At this rate the wall would melt through in approximately 75 seconds. This value is somewhat less than the thermal time constant of the vessel wall given by 


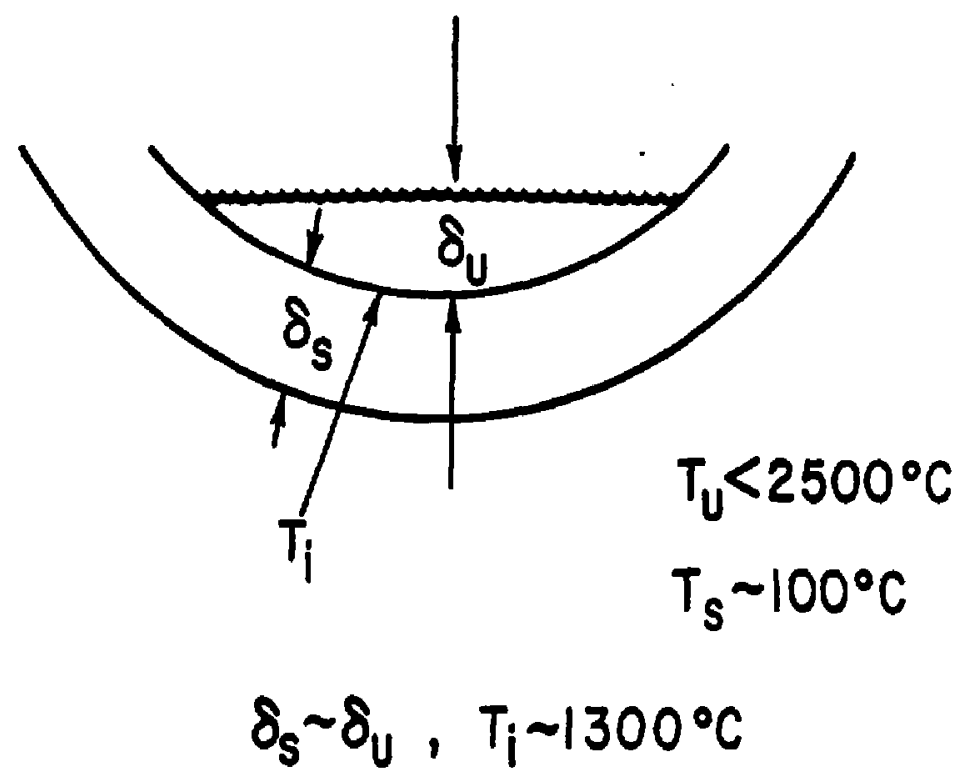

Fig. 6.1 Illustration of the thermal melt-through problem of the process module. 
Table 6.1

PENETRATION RATES ABOVE EUTECTIC TEMPERATURE

Temperature, ${ }^{\circ} \mathrm{C}$

Rate, mils/min.

ข 800

n 0.1

$\sim 900$

20.5

$\sim 1020$

23.0

$\sim 1100$

$\sim 8.0$

$\sim 1150$

$10 \mathrm{mils} / \mathrm{s} \leftarrow$-Uranium

Melting Temperature 


$$
\tau \sim \frac{\delta_{s}^{2} \rho_{s} C_{s}}{k_{s}} \sim 100 \mathrm{~s}
$$

The ejtectic penetration and themal boundary layer profiles are illustrated in Fig. 6.2

As the melting attack proceeds in time, significant upward heat losses from the uranium metal are affected by radiation and in the presence of water also by convection as 11 lustrated in Fig. 6.3. The combined heat loss can be estimated from

$$
q=A\left[\sigma e\left(T_{u}^{4}-T_{e}^{4}\right)+h\left(T_{u}-T_{s}\right)\right]
$$

where $A$ is the surface area of the melt, $\sigma$ is the Stefan-Boltzmann constant, $h$ is the heat transfer coefficient, $T_{s}$ is the saturation temperature of water. and $\varepsilon$ is the emissivity which is set equal to unity.

Procseding on the basis that the rapid attack by eutectic formation $(10 \mathrm{~m} f 1 \mathrm{~s} / \mathrm{s})$ will persist as long as the bulk uranium metal temperature remains above the melting temperature, a maximum penetration distance can be calculated by accounting for surface heat losses from the melt using Eq. 6.2 as well as accounting for sensible heat absorbed by the meit-in process of the steel wall. This leads to a maximum time of about 30 seconds for rapid attack which corresponds to half the vessel wall thickness. As 1llustrated in Fig. 6.2, for these conditions the themal wave front is traveling ahead of the eutectic penetration wave. Hence ignoring the heat loss to the vessel wall ahead of the meit front add further conservatism to the evaluation.

In sumary, a very conservative calculation illustrates that at most half the wall would experience attack by rapid eutectic formation. Subsequent attack would be very slow, and any further significant attack would be completely stopped by continued heat losses from within the vessel as well as from the outside. The potential for themal melt-through of the vessel wall is therefore considered vanishingly small. 


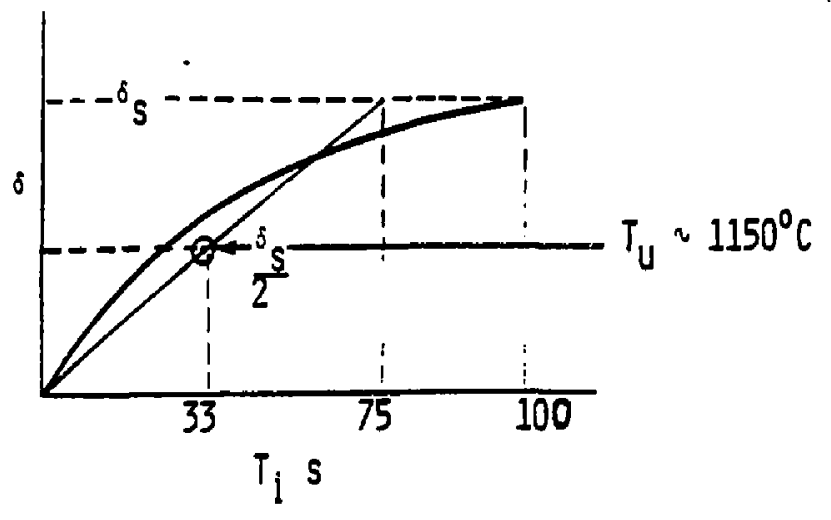

Fig. 6.2 Comparison of eutectic penetration and themal boundary profiles. 


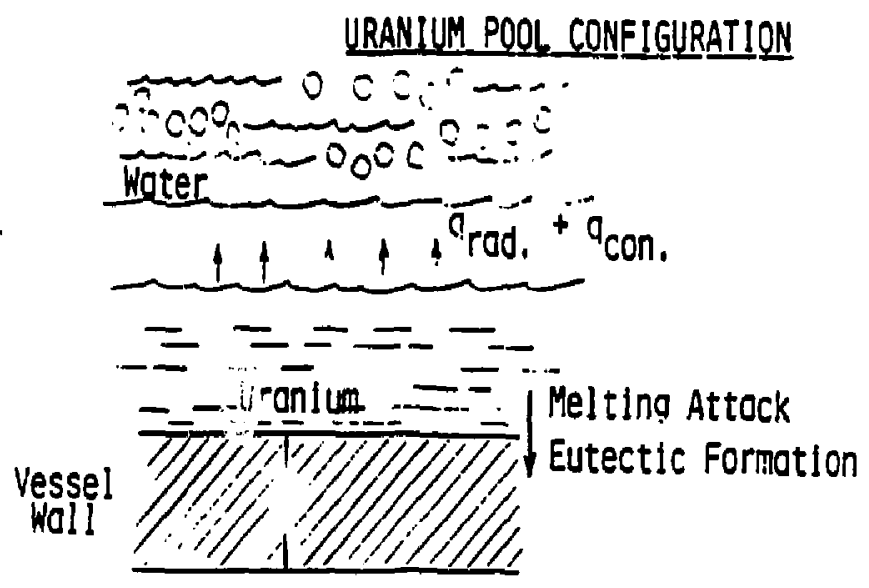

Fig. 6.3 Illustration of model used to analyze the eutectic melting attack on the vessel wall. 


\section{$6.2 \quad$ References}

6.1 C. M. Walker, G. H. Golden and N. J. 01son, "U-Pu-Zr Metal Alloy: A Potential Fuel for LMFBRs," ANL-76-20, November 1975. 


\subsection{IMPLOSION CONSIDERATIONS}

As part of the overall accident evaluation considerations were given to a vessel implosion scanario resuiting from a ruptured window. Considera. tions have included vessel pressurization rate, the potential for rapid entrainment of the melt and the subsequent potential for uranium metal oxidation.

\subsection{Vessel Pressurization}

Assuming a $15 \mathrm{~cm}$ diameter window is broken, elementary calculations show that vessel pressurization will occur on the order of 5 secs.

Approximating the gas flow using isothermal gas flow conditions

$$
W=\eta P_{0} A / \sqrt{R T}
$$

where $n=0.6, P_{0}=0.1 \mathrm{MPa}, A=0.018 \mathrm{~m}^{2}$ and $T=300 \mathrm{~K}$, we obtain a flow rate of $3.6 \mathrm{~kg} / \mathrm{s}$. Assuming a pod volume of $16 \mathrm{~m}^{3}$ which corresponds approximately to $18 \mathrm{~kg}$ of air at ambient pressure condition (l atm), results in a fill time of the order of 5 secs.

\subsection{Entrainment Potential of Melt}

The maximum jet velocity at pressure equilibration is given by

$$
U=\frac{P_{t}-P_{P}}{G}+U_{t}
$$

where $P_{t}(=0.06 \mathrm{MPa})$ is the throat pressure, $P_{p}(=0.01 \mathrm{MPa})$ is the assumed pod pressure, $U_{t}(=293 \mathrm{~m} / \mathrm{s})$ is the throat velocity and $G(=200$ $\left.\mathrm{kg} / \mathrm{s}-\mathrm{m}^{2}\right)$ is the mass flow rate, and results in a velocity of $537 \mathrm{~m} / \mathrm{s}$.

The flow area corresponding to this velocity is given by 


$$
A_{c}=\frac{W}{a_{c} V_{c}}
$$

where $p_{c}\left(=0.1 \mathrm{~kg} / \mathrm{m}^{3}\right)$ and resuits in $A_{c} \times 0.058 \mathrm{~m}^{2}$.

The one-dimensional velocity in the pod can then be approximated by

$$
U_{p}=\frac{A_{C}}{A_{p}} U_{C}
$$

where $A_{p}\left(=5.94 \mathrm{~m}^{2}\right)$ and results in $U_{p}=5.2 \mathrm{~m} / \mathrm{s}$.

The required velocity to entrain any significant quantity of uranium metal from the crucible can be estimated from

$$
U_{g}=\frac{3.7 \sqrt[4]{g \circ\left(\rho_{u}-\rho_{g}\right)}}{\sqrt{\rho_{g}}}
$$

Where $p_{u}\left(=18,000 \mathrm{~kg} / \mathrm{m}^{3}\right)$ is the uranium metal density, $\sigma(=1 \mathrm{~N} / \mathrm{M})$ is the uranium metal surface tension, and results in $U_{g} \approx 224 \mathrm{~m} / \mathrm{s}$.

Since the entrainment velocity is seen to be almost two orders of magnitude larger than the one-dimensional vessel velocity produced by the postulated implosion scenario, no substantial entrainment would occur. The resultant oxidation potential is therefore considered to be negligible under such conditions. 


\subsection{HYOROGEN FORMATION AND COMBUSTION}

\section{$8.1 \quad$ Introduction}

In connection with the postulatef occurrence of an energetic steam explosion within the process module, it is also necessary to consider potential explosion augmentation due to significant oxidation of the molten metal resulting in hydrogen formation and combustion. This is particularly so since fine fragi antation of the metal is associated with the steam explosion occurrence. As illustrated in Appendix $B$, the rate and the amount of oxidation is quite sen itive to the particle size, clearly illustrating that for steam explosion conditions, rapid hydrogen formation is indeed likely. As such a detailed calculation of the combustion potential would require specification of partic' s sizes following the steam explosion, which are generally not available.

\section{$8.2 \quad 3$ Jounding Analysis}

However, the problem can be bounded by assuming that the water participating in the steam explosion ( $\sim 0.6 \mathrm{~kg}$ as calculated in Section 4 ) is available to produce hydrogen which results in $0.033 \mathrm{~kg}$-moles. This amount of hydrogen would correspond to approximately $5 \%$ volume fraction distributed in a single pod at 1 bar pressure. At these concentrations the hydrogen is barely combustible (see Fig. 8.1). Assuming an adiabatic combustion, the pressure increase would only be about 1.5 bars, which would not threaten the structural integrity of the pod.

\subsection{References}

8.1 "Supplement to Analysis of Three Mile Island - Unit 2 Accident," NSAC-T Supplement, October 1979. 


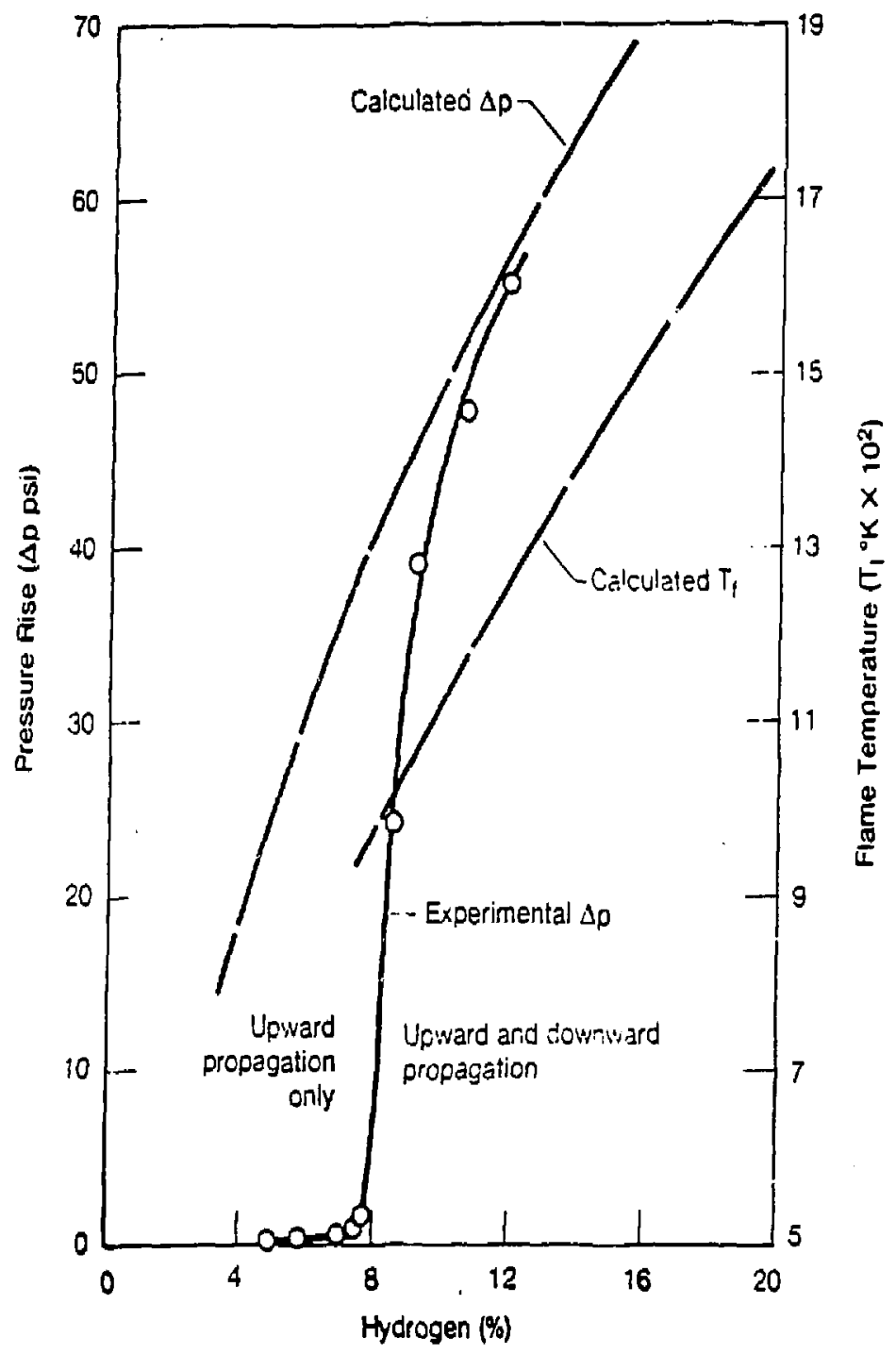

Fig. 8.1 Pressure rises resulting from ignition of hydrogen-air in 12-ft-diameter sphere at $18^{\circ} \mathrm{C}$. [Taken from Ref. 8.1.] 


\subsection{STRUCTURAL CONSIDERATIONS}

\section{$9.1 \quad$ Introduction}

The Special Isotopic Separation Laboratory (SISL) Process Module Pod is a simple 304L stainless steel shell designed to enclose the main components of the separation process under vacuum service. A schematic diagram of the SISL process module pod is shown in Fig. 9.1. The main components include (a) a cylindrical steel stell which could range in size from 9 to 15 feet in diameter with a length of 9 feet and a nominal shell thickness of 0.75 inch, (b) four utility port penetrations having a nominal diameter of 12 inches and (c) two end rings which are used to bolt up to six pods together into a process module. The vessel end cap is a torispherical (or spherical) head with a single optical duct penetration. The process module pod is supported by four, approximately one-foot diameter columns. The entire tank shell is protected by a water-cooled Temp-Plate liner.

The main internal components of the process module pad include (a) the water cooled copper crucible which hoids the uranium melt, $(b)$ an ion extractor and (c) collector all surrounded with a vapor enclosure. Aside from a steel support structure the main internal components of a pod are made of graphite panels having a nominal thickness which varies from 1 to $3 \mathrm{~cm}$.

As discussed in the previous chapters, the water-molten uranium interaction can take place in either of two places within the vessel. The first, and most cbvious, is the centrally located, water-cooled, crucible containing the molten uranium. A second is in the bottom of the pod shell if the crucibie were to rupture and drop its molten uranium contents into a waiting pọol of water. The first case is considered a design basis accident while the second case is considered to be a "once-in-a-lifetime" accident scenario.

An analysis of the structural respanse of the SISL process module pod must consider (a) dynamic pressure loadings resulting from any vapor explosion occurring in either the crucible or at the bottom of the shell, (b) long term pressurization of the pod due to water vaporization as the melt 
Pod Cenceptual Desten

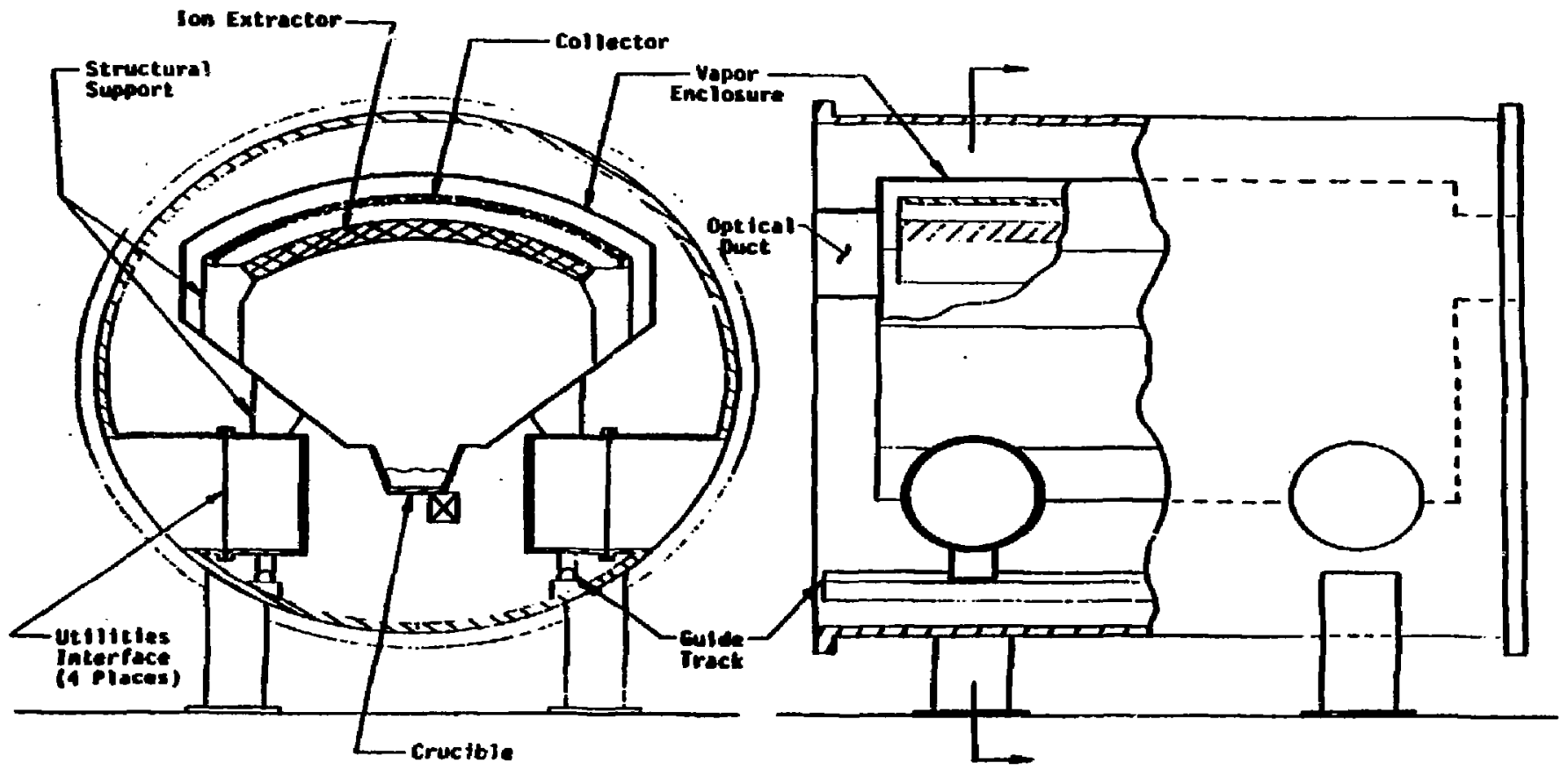

Fig. 9.1 SISL Process Module Pod is a self-contained unit. 
cools and (c) graphite shrapnel generated as the result of the vapor explosion.

Consideration of the structural capability of the shell in response to a vapor explosion can be approached in either of two ways. The first is to calculate the dynamic response of the shell in response to a loading characterized as a pressure-time variation. The second, and perhaps more conservative approach, is to consider the shell from a purely energy absorption point of view. Potential damage to the shell from graphite shards resulting from fractured graphite structural material requires a somewhat more sophisticated evaluative procedure. These analyses and results will be given in the following sections.

\subsection{Material Properties and Design Parameters}

The shell of the SISL Process Module Pod is made of 304L stainless steel. The shell is protected from the high temperatures achieved within the vapor enclosure by a Temp-Plate liner which is a water-cooled embossed double sheet of 304 or 316 stainless steel having a total metal thickness of 0.183 in. $(0.465 \mathrm{~cm})$. The Temp-Plate keeps the shell wall at a temperature of about $70^{\circ} \mathrm{F}\left(21.1^{\circ} \mathrm{C}\right)$. The material properties of $304 \mathrm{~L}$ stainless steel of various temperatures are given in Table 9.1.

The graphite structural material within the pod which comprises ion extractor, collector and yapor enclosure is Stackpoie Grade 2020. The thickness of the graphite ranges from 1 to $3 \mathrm{~cm}(0.394$ to $1.18 \mathrm{in}$.$) . The total$ volume of graphite structure within the tank is $0.37 \mathrm{~m}^{3}\left(13.07 \mathrm{ft}^{3}\right)$ or 654 $\mathrm{kg}(1442 \mathrm{lb})$. Table 9.2 lists the pertinent graphite material properties while Figs. 9.2 and 9.3 show its tensile and compressive strengths both parallel (with) and perpendicular (cross) to the grain of the specimen. It should be noted that graphite is a brittle material in that it exhibits only a small amount of plastic deformation before fracturing. Also, like most ceramic-type materials, its compressive strength is much greater than its tensile strength. 
Table 9.1

MATERIAL PROPERTIES OF 304L STAINLESS STEEL [9.1]

\begin{tabular}{|l|c|c|c|}
\hline \multicolumn{1}{|c|}{ Property } & \multicolumn{3}{|c|}{ Temperature $\left({ }^{\circ} \mathrm{F} /{ }^{\circ} \mathrm{C}\right)$} \\
\cline { 2 - 4 } & $70 / 21.7$ & $200 / 93.3$ & $400 / 204.4$ \\
\hline Yield Stress, $\sigma_{y}$ (psi/MPa) & $35,000 / 241.4$ & $28,000 / 193.1$ & $23.000 / 158.6$ \\
Elastic Modulus. E (psi/MPa) & $27.4\left(10^{6}\right) / 0.189\left(10^{6}\right)$ & $27.7\left(10^{6}\right) / 0.188\left(10^{6}\right)$ & $26.4\left(10^{6}\right) / 0.182\left(10^{6}\right)$ \\
U1timate Stress, $\sigma_{u}(\mathrm{psi} / \mathrm{MPa})$ & $85,000 / 586.2$ & $79,000 / 544.8$ & $74,000 / 510.3$ \\
U1t. Strain $(x)$ & 60 & 60 & 60 \\
Density $(\mathrm{g} / \mathrm{cc})$ & 8.03 & 7.99 & 7.95 \\
\hline
\end{tabular}


Table 9.2

STRUCTURAL GRAPHITE MATERIAL PROPERTIES [9.2]

\begin{tabular}{|c|c|c|}
\hline Property & With Grain & Cross Grain \\
\hline Tensile Strangth (psi/MPa) & $4,000 / 27,59$ & $3,900 / 26,90$ \\
\hline Compressive Strength (psi, MPa) & $13,000 / 89.65$ & $9,500 / 65.2$ \\
\hline \multicolumn{3}{|l|}{ Modulus of Elasticity } \\
\hline Tension $\left(10^{6} \mathrm{psi} / 10^{3} \mathrm{MPa}\right)$ & $1.16 / 8.0$ & $1.10 / 7.586$ \\
\hline Compression $\left(10^{6} \mathrm{psi} / 10^{3} \mathrm{MPa}\right)$ & $1.34 / 9.241$ & $1.31 / 9.034$ \\
\hline \multicolumn{3}{|l|}{ Ultimate Strain $(x)$} \\
\hline Tensile & 0.39 & 0.35 \\
\hline Compressive & 1.92 & 1.84 \\
\hline Apparent Sp. Gravity & \multicolumn{2}{|c|}{1.77} \\
\hline Real So. Gravity & \multicolumn{2}{|c|}{2.14} \\
\hline
\end{tabular}




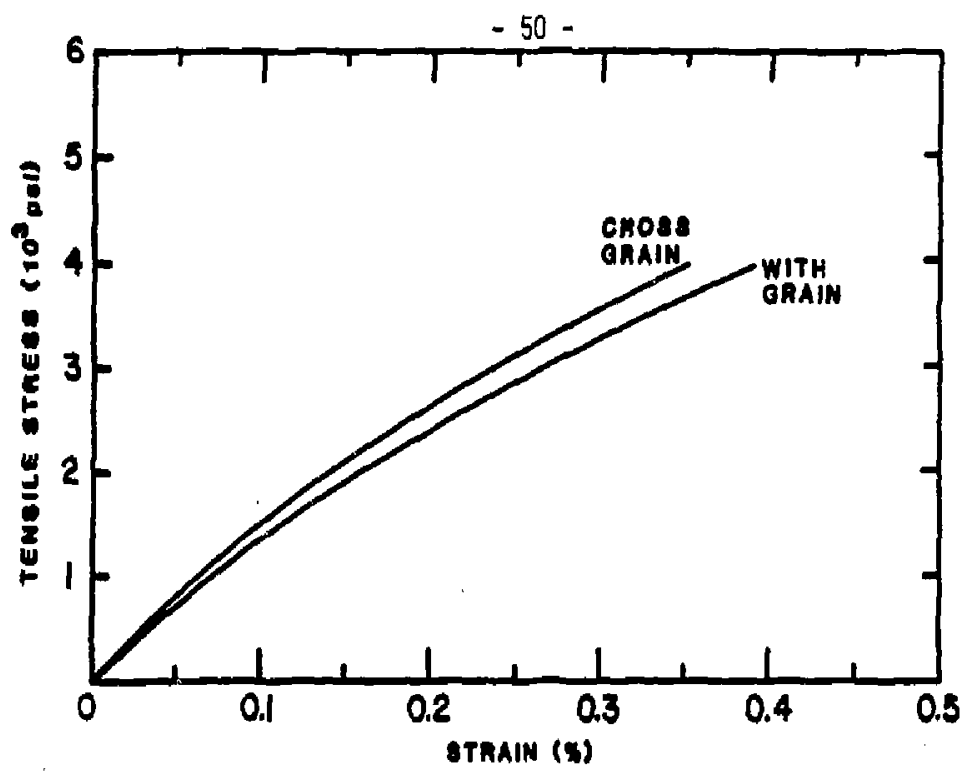

Fig. 9.2 Tensile strength of grade 2020 graphite [9.2].

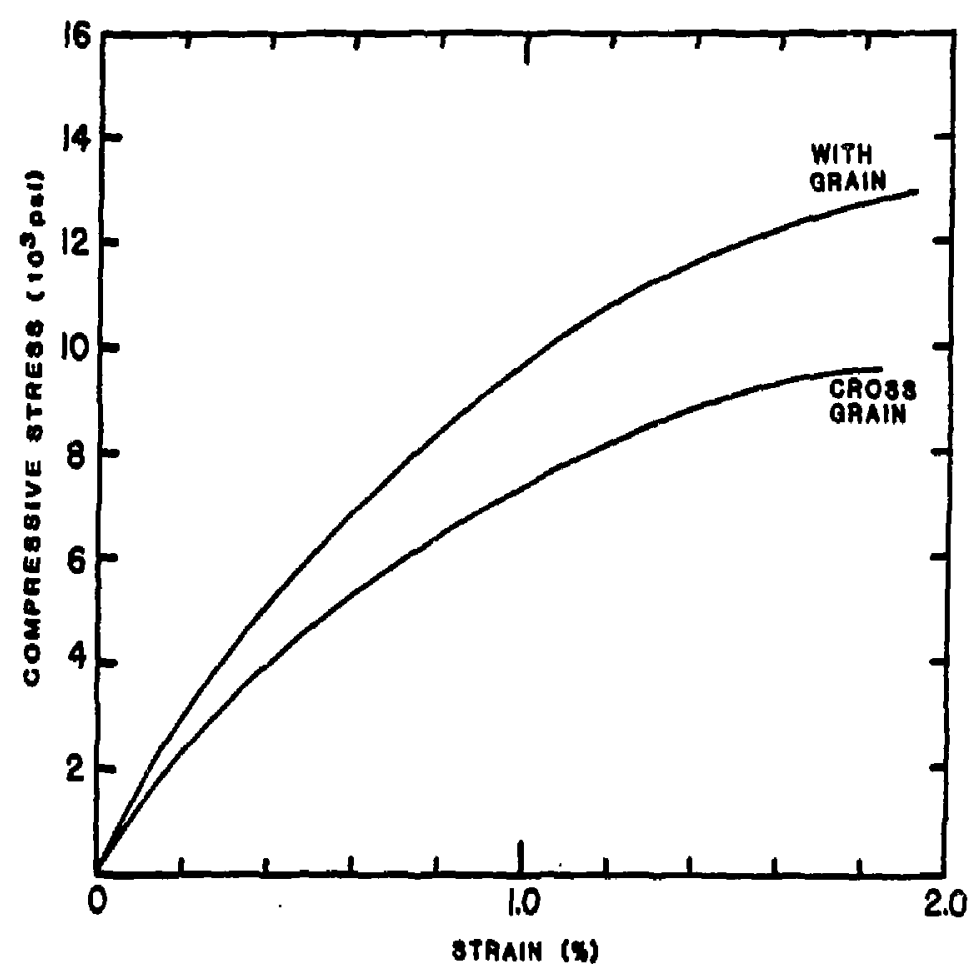

Fig. 9.3 Compressive strength of grade 2020 graphite [9.2]. 
The SISL pod is designed to operate as a vacuum vessel under normal conditions and as such must resist buckling under an external pressure load. The vessel should be designed to resist an external pressure four times the expected 15 psia (0.1035 $\mathrm{MPa}$ ) external pressure, or $60 \mathrm{psia}(0.414 \mathrm{MPa})$ [9.3]. Assuming that the vessel wall will operate at $70^{\circ} \mathrm{F}\left(21.1^{\circ} \mathrm{C}\right)$, then the minimum vessel thickness for a 9 foot $(2.744 \mathrm{~m})$ diameter vessel will be 0.386 in. $(0.9804 \mathrm{~cm})$ while a 15 foot $(4.572 \mathrm{~m})$ diameter vessel would require a thickness of $0.50 \mathrm{in} .(1.27 \mathrm{~cm})$. Thus, under vacuum service, the nominal thickness of $0.75 \mathrm{in} .(1.905 \mathrm{~cm})$ selected for the SISL pod wall provides a safety margin of about 20.5 for the 9 foot vessel and 11.5 for the 15 foot diameter vessel. Table 9.3 lists the maximum pressures sustainable by vessels having various diameters and wall thickness:

\subsection{Dynamic Pressure Loading}

For a water-molten uranium interaction which takes place in the crucible the resulting dynamic loading on the vessel wall is a function of (a) the initial pressure in the interaction 20ne, (b) the total time of the interaction and $(c)$ the energy conversion efficiency of the process. As indicated in Section 4, the dynamic pressure loaciings estimated for the design basis accident are well below the static pressures summarized in Table 9.3. However, for design purposes, an arbitrary pressure loading is specified with a triangular shape, 30 microseconds wide, reaching a maximum pressure, $P_{\max }$ ' at 15 microseconds. The maximum pressures which could be attained at the vessel wall are conservatively estimated to be up to about $6 \mathrm{MPa}$ ( $~ 900 \mathrm{psig}$ ) with a total energy release of $450 \mathrm{~kJ}$.

The dynamic, elastic response of a circular cylindrical shell of radius, $r_{1}$, and thickness, $h$, is given by

$$
\frac{d^{2} \sigma}{d t^{2}}+\frac{E \sigma}{\rho r_{1}^{2}}=\frac{E}{\rho r_{l} h} p(t)
$$


Table 9.3

DESIGN PRESSURE (pSig) OF SISL VESSEL FOR VARIOUS

DIAMETERS AND THICKNESSES

\begin{tabular}{|cccc|}
\hline & \multicolumn{3}{c|}{ Vessel Wall Thickness in $(\mathrm{cm})$} \\
$\begin{array}{c}\text { Pod Diameter } \\
\mathrm{ft}(\mathrm{m})\end{array}$ & $0.5(1.27)$ & $0.75(1.905)$ & $1.0(2.54)$ \\
\hline $9.0(2.743)$ & 324 & 486 & 648 \\
$12.0(3.658)$ & 243 & 365 & 486 \\
$15.0(4.572)$ & 194 & 292 & 389 \\
\hline
\end{tabular}


where $E$ is Young's Modulus, $\rho$ is the density of the material, $\sigma$ is the hoop stress and $p(t)$ is an arbitrary pressure loading where a positive value indicates internal pressure. The natural frequency of the shell is given by

$$
w_{n}=\sqrt{\frac{E}{\rho r_{1}^{2}}} \mathrm{rad} / \mathrm{sec} .
$$

Figure 9.4 shows the dynamic response of the 9 foot diameter vessel wall to pressure pulses ranging from 300 to 900 psig. The maximum stress attained is about \pm 3540 psi for the 900 psig peak pressure case. Considering the fact that the vessel is initially under a compressive stress of -1080 psi if the vessel is evacuated the maximum range is +2460 psi to -4620 psi well within the yield stress for the vessel material. Similarly, fig. 9.5 shows the response of the 15 foot diameter vessel to pulses with maximum pressures ranging from 300-900 psig. Again, these stresses are well below the stress limits for the 304L stainiess steel shell.

Thus, it is clear that for the expected conservative dynamic loadings expected at the SISL process pod wall the resulting stresses will not challenge the integrity of the vessel. The response is entirely elastic and no energy is expected to be absorbed in the walls causing permanent deformation.

Pod response to a water-molten uranium interaction at the bottom of the shell can be conservatively estimated by considering a uniform dynamic loading over the inside surface of the shell. If a water-molten uranium event were to take place at the bottom of the tank in a pool $10 \mathrm{~cm}$ deep $(3.94 \mathrm{in.}$ ), it is expected that the applied pressure pulse would be 1600 psig with a width of $0.1 \mathrm{msec}$. Neglecting local distortions due to bending because of the unsymmetric load, a conservative estimate of the maximum stress in the shell can be made by applying the impulse to the entire shell. Although this may underestimate local bending stresses, it overestimates hoop stresses. Figure 9.6 shows the response for the $9 \mathrm{ft}$. diameter vesse $12.74 \mathrm{~m})$ while fig. 9.7 is that of the $15 \mathrm{ft}$. (4.572) diameter vessel. In neither case does the stress exceed that of the elastic limit of the shell. Further, it is expected that the energy released in the interaction will most likely result as kinetic 


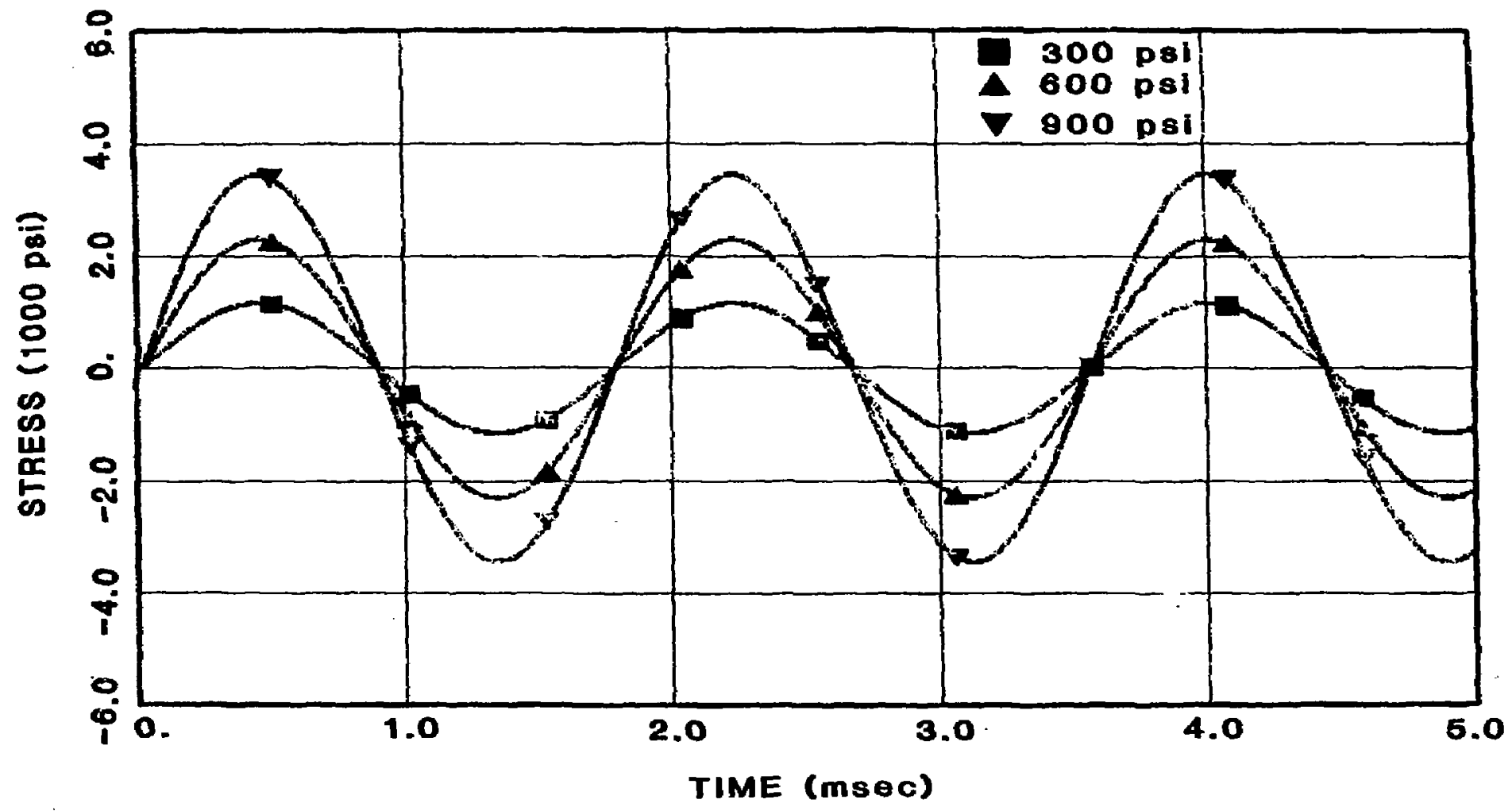

Fig. 9.4 Dynamic response of 9 foot diameter SISL vessel neglecting the initial compressive stress. 


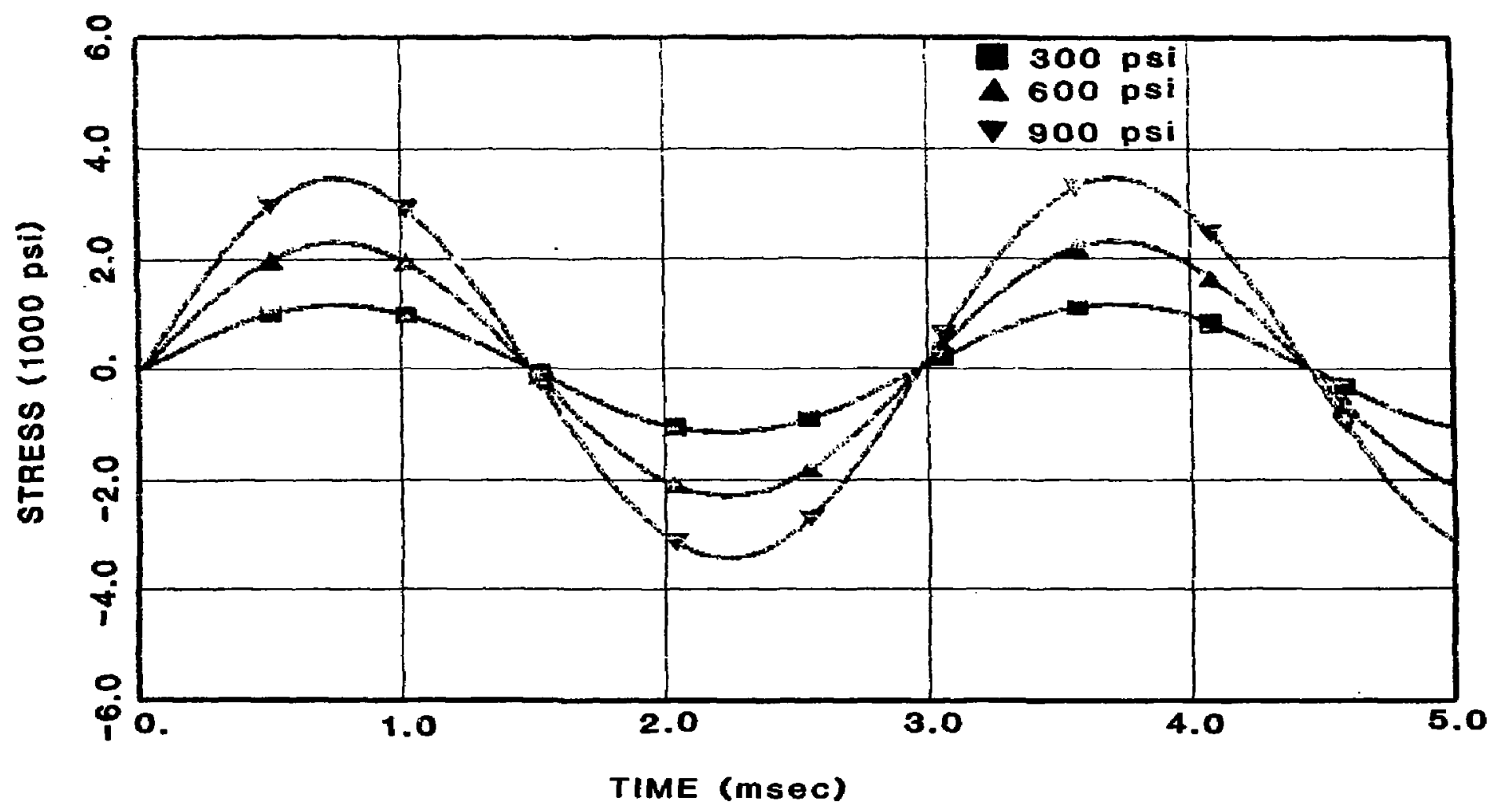

Fig. 9.5 Dynamic response of 15 foot dianeter SISL tank neglecting the initial compressive stress. 


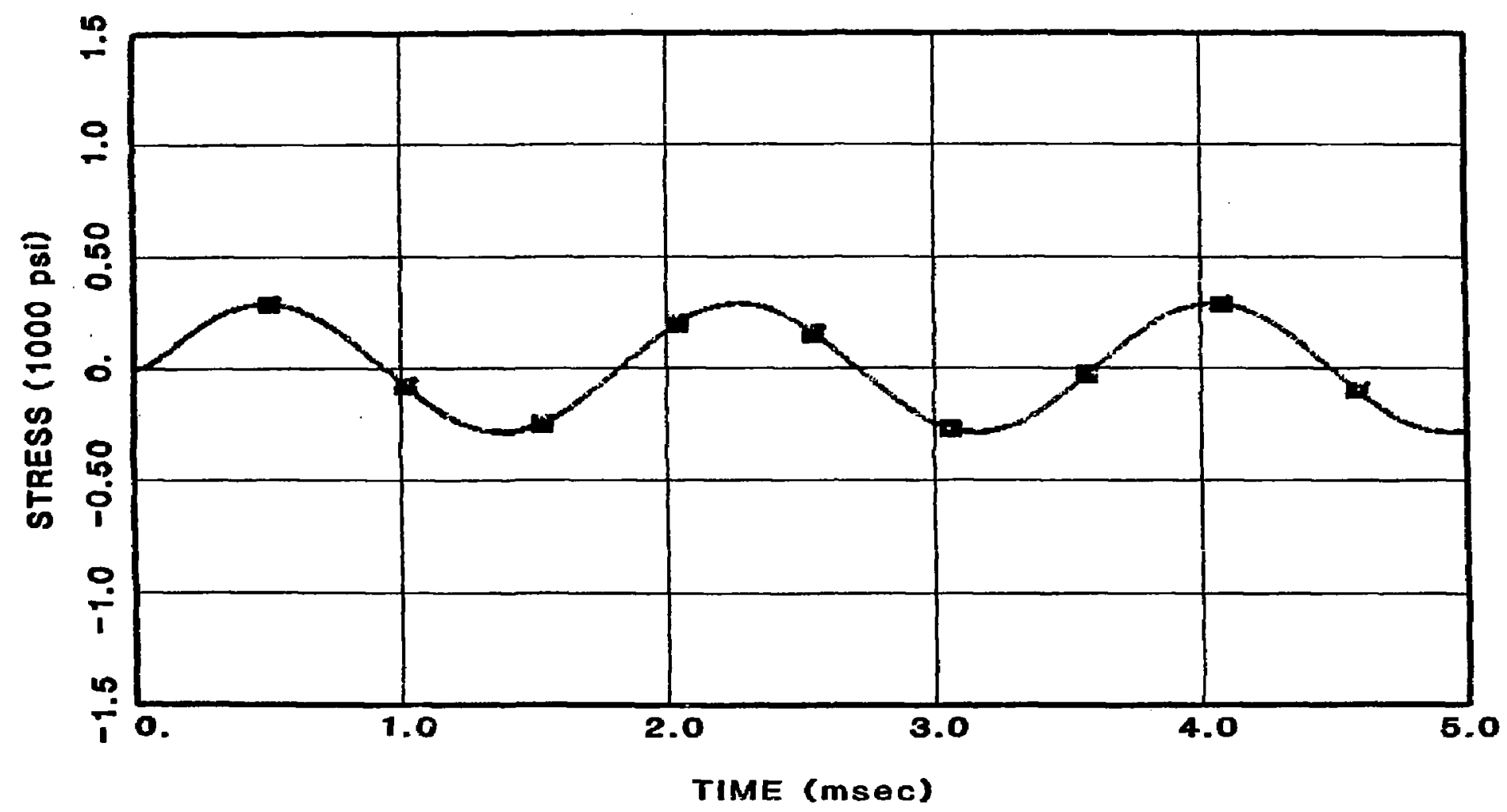

Fig. 9.6 Response of 9' diameter vessel to 1600 psi pressure for $0.1 \mathrm{msec}$. 


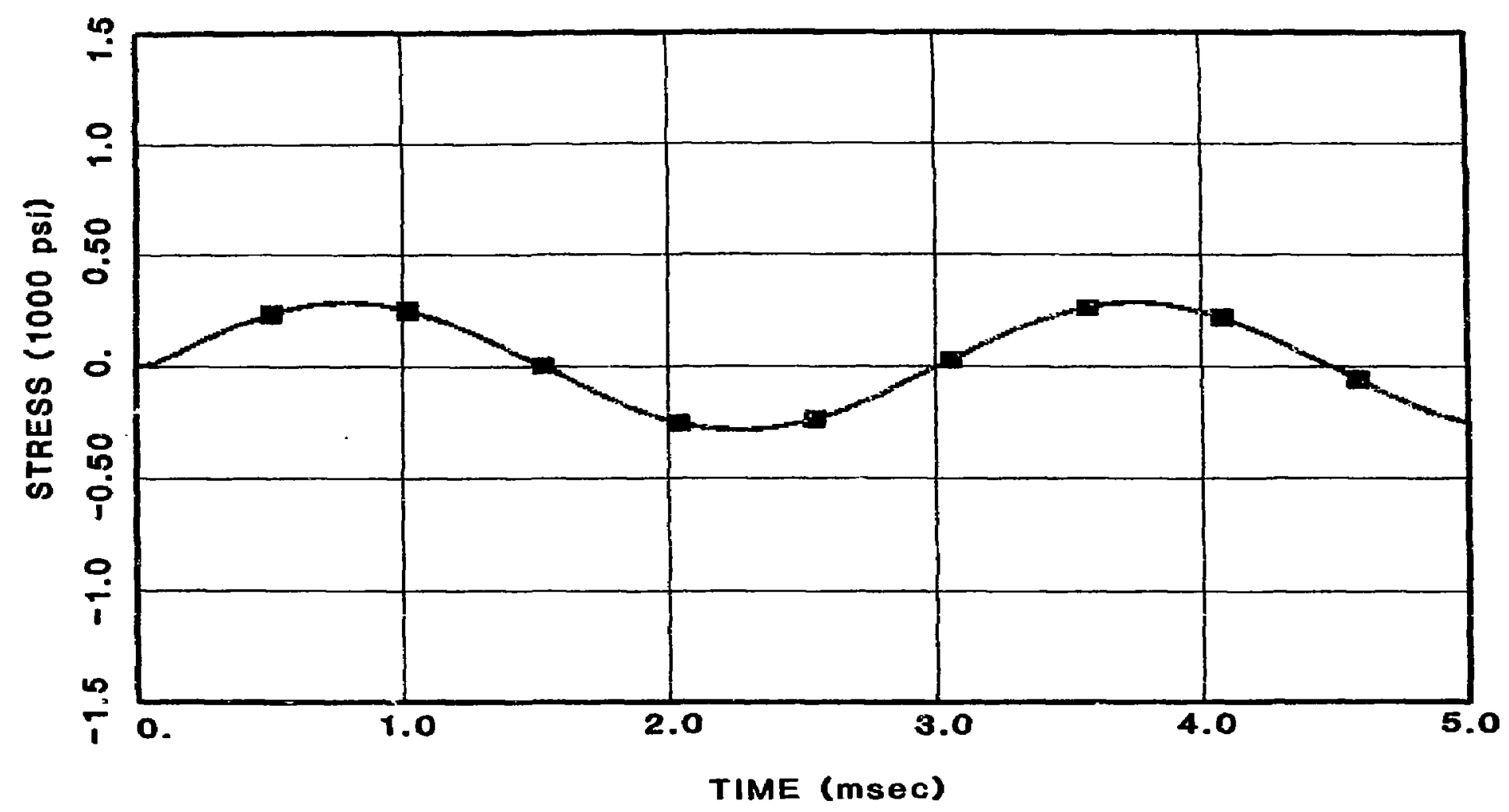

Fig. 9.7 Response of $15^{\prime}$ diameter vessel to 1600 psi pressure for 0.1 msec. 
energy of the water and uranium rather than in any permanent distortion of the shell. Thus, it is unlikely that the shell will be damaged by an event taking place at the wall.

Another way of looking at the problem is to estimate the energy absorption capability of the shell. As the shell is distorted it abscrbs energy and, if it distorts plastically, this will result in the permanent deformation of the shell.

Table 9.4 shows the energy absorption capability of the pod shell up to the yield point of the material. Shown is the elastic absorption capability of vessels ranging in size from 9 feet $(2.74 \mathrm{~m})$ in diameter up to 15 feet $(4.57 \mathrm{~m})$ with vessel wall thickness varying from $0.5 \mathrm{~m}(1.27 \mathrm{~cm})$ to 1.0 in $(2.54 \mathrm{~cm})$. At the nominal vessel thickness of $0.75 \mathrm{in}(1.91 \mathrm{~cm})$ the maxinum energy absorbed ranges from $69.4 \mathrm{~kJ}$ up to $115.7 \mathrm{~kJ}$. Since these energies are less than the expected energy release of $450 \mathrm{~kJ}$ the vessel could be expected to distort plastically.

If the vessel were to distort plastically then the maximum absorbed energy per unit volume of material would include the entire area underneath the stress strain curve. The results of this calculation are shown in Table 9.5. At a nominal vessel thickness of $0.75 \mathrm{in}(1.91 \mathrm{~cm})$ the total plastic absorption capability ranges from $111.6 \mathrm{MJ}$ to $186.0 \mathrm{MJ}$. These values are 248 to 413 times as large as the expected energy release of $450 \mathrm{~kJ}$. This suggests that the maximum strain of the vessel would be quite small.

Table 9.6 shows the maximum uniform strain expected if all the energy released in the water-molten uranium interaction is absorbed in the walls. For a nominal wall thickness of 0.75 in $(1.91 \mathrm{~cm})$ the maximum uniform strain ranges from a high of 0.68 percent for a 9 foot $(2.74 \mathrm{~cm})$ dlameter vessel to a low of 0.36 percent for a 15 foot $(4.57 \mathrm{~cm})$ diameter vessel. These are very small strains and will not endanger the integrity of the vessel.

It should be kept in mind, however, that the full energy release of $450 \mathrm{~kJ}$ will not be absorbed in the vessel. A significant amount of the energy 
Table 9.4

PROCESS POD ELASTIC ENERGY ABSORPTION CAPABILITY AT $70^{\circ} \mathrm{F}\left(27^{\circ} \mathrm{C}\right)$

\begin{tabular}{|c|ccc|}
\hline \multirow{2}{*}{$\begin{array}{c}\text { Vessel } \\
\text { Diameter } \\
\text { ft }(\mathrm{m})\end{array}$} & \multicolumn{3}{|c|}{ Absorbed Elastic Energy (kJ) } \\
\cline { 2 - 4 } $9(2.74)$ & $0.5(1.27)$ & $0.75(1 . \mathrm{si})$ & $1.0(2.54)$ \\
\hline $12(3.66)$ & 61.7 & 69.4 & 92.6 \\
\hline $15(4.57)$ & 77.1 & 92.6 & 123.4 \\
\hline
\end{tabular}


Table 9.5

PROCESS POD TOTAL ENERGY ABSORPTION CAPABILITY AT $70^{\circ} \mathrm{F}\left(21^{\circ} \mathrm{C}\right)$

\begin{tabular}{|c|ccc|}
\hline & \multicolumn{3}{|c|}{ Total Absorbed Energy (MJ) } \\
\cline { 2 - 4 } $\begin{array}{c}\text { Vessel } \\
\text { Diameter } \\
\mathrm{ft}(\mathrm{m})\end{array}$ & \multicolumn{3}{|c|}{ Vessel Thickness, in. (cm) } \\
\hline $9(2.74)$ & 74.4 & 111.6 & 148.8 \\
$12(3.66)$ & 99.2 & 148.8 & 198.4 \\
$15(4.57)$ & 124.0 & 186.0 & 248.0 \\
\hline
\end{tabular}


Table 9.6

PROCESS POD MAXIMUM UNIFORH HOOP STRAIN TO ABSORB $450 \mathrm{~kJ}$

\begin{tabular}{|c|ccc|}
\hline \multirow{2}{*}{$\begin{array}{c}\text { Vesse) } \\
\text { Diameter } \\
\mathrm{ft}(\mathrm{m})\end{array}$} & \multicolumn{3}{|c|}{ Pod Hoop Strain (\%) } \\
\cline { 2 - 3 } & $0.5(1.27)$ & $0.75(1.91)$ & $1.0(2.54)$ \\
\hline $9(2.74)$ & 0.552 & 0.348 & 0.245 \\
$12(3.66)$ & 0.399 & 0.245 & 0.168 \\
$15(4.57)$ & 0.377 & 0.184 & 0.122 \\
\hline
\end{tabular}


will be absorbed in the distortion of the internal structure, kinetic energy of the particles and temperature increase of the material. Thus, actual pod shell strains will likely be much less than those calculated here.

\subsection{Long Term Vessel Pressurization}

The long term pressurization of the SISL pod could occur as the result of steam production or any other subsequent gas generation. The main problem with the longer term pressurization has to do with stress concentrations at points such as the end rings and penetrations. As an example, Fig. 9.8 shows the maximum longitudinal stress, $\sigma_{L}$ and hoop stress, $\sigma_{h}$ near the end rings of an individual pod as a function of initial pressure. Because of bending stresses imposed upon the vessel the longitudinal stress will be more than twice that of the hoop stress. For a nominal 9 foot diameter vessel with a 0.75 in thick wall the maximum sustainable pressure is about 240 psig while a 1.0 in thick vessel will reach yield at an internal pressure of about 325 psig.

Since the maximum long term internal pressure expected in the SISL pod as the result of any possible accident will be less than 50 psig there is absolutely no threat of vessel failure at any point. This pressure is nearly a factor of five lower than the yield pressure for a 9 foot diameter vessel and about a factor of three smaller than that for the 15 foot diameter vessel. Thus, the safety margins are adequate to assure that the vessel will not fail or be permanently deformed as the result of long term pressurization provided the vessel is designed according to the ASME code and is properiy vented.

\subsection{Internal Missiles}

As already demonstrated neither the dynamic pressure loads or long term loads in the SISL process module pod wall will cause fallure. However, there is the possibility that missiles generated during the vapor explosion may cause failure of the shell by chunks, or shards, of brittle graphite which would hit the wall at velocities which could potentially cause serious local damage even for the most probable events. 


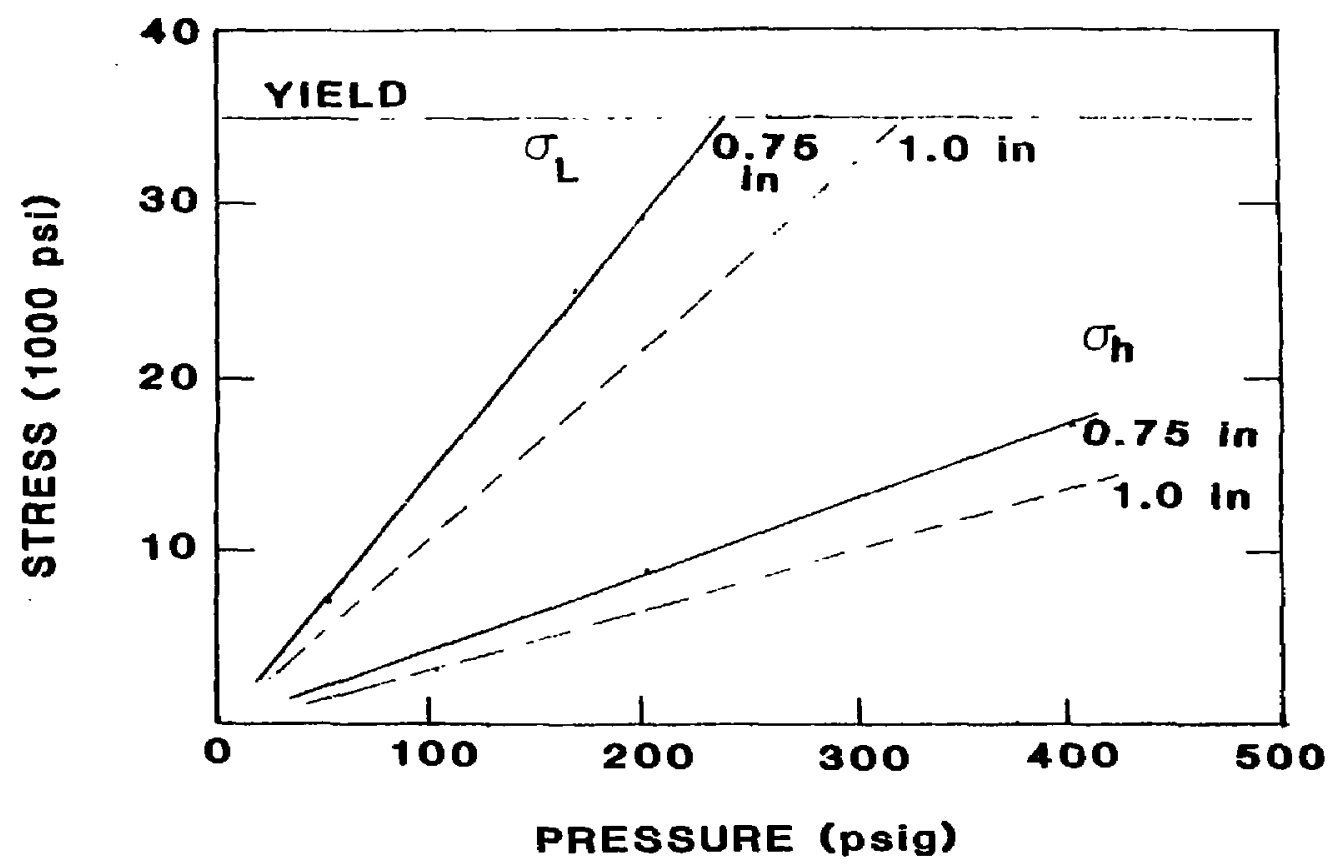

Fig. 9.8 Process Module Pod end meridional stress, $\sigma_{L}$, and hoop stress, $\sigma_{h}$, for 9 foot diameter tank. 
The velocity at which a graphite shard hits the wall is dependent upon the pressure impulse it experiences. The closer the piece is to the pressure source the higher the impulse. For example, graphite structure near the vapor explosion site could see pressures as high as 1000 psi resulting in an impulse of $0.5 .1 \mathrm{~b}-\mathrm{sec} / \mathrm{in}^{2}$ of shard surface area if the impuise is triangular with a width of $1 \mathrm{msec}$. This would cause a piece of graphite 0.394 in (1 $\mathrm{cm})$ thick and $10 \mathrm{in}^{2}\left(64.5 \mathrm{~cm}^{2}\right)$ in area to reach a velocity of 639 et $/ \mathrm{sec}(194.8 \mathrm{~m} / \mathrm{sec})$. Figure 9.9 shows the velocity of the graphite shards as a function of the maximum impulse pressure.

Since graphite is such a brittle material it can be expected to shatter if the stress exceeds the maximum tensile or compressive stress. The limiting compressive stress is 13,000 psi $(89.7 \mathrm{MPa}$ ) while the speed of sound, $c$, in graphite is $6979 \mathrm{ft} / \mathrm{sec}(2127.0 \mathrm{~m} / \mathrm{sec})$. With a density, $p$, of 3.43 $1 \mathrm{~b}-\mathrm{sec}^{2} / \mathrm{ft} \mathrm{t}^{4}$ the limiting impact velocity is

$$
V_{\text {limit }}=\frac{\sigma_{f}}{p C}=78.21 \mathrm{ft} / \mathrm{sec}(23.8 \mathrm{~m} / \mathrm{sec})
$$

Thus, if the impact velocity of the graphite on the steei shell exceeds this value, the graphite will likely shatter.

On the other hand, it is possible to estimate the velocity needed to penetrate the steel shell of the SISL pod by using a method outlined by Zukas, et. al., [9.5]. In this analysis, a projectile impacting a target plate is assumed to be stopped if its velocity, $V_{s}$, is less than the Ballistic Limiting Velocity (BLV), $V_{\ell}$. The BLV is determined with the use of an empirically derived formulation which takes into account the projectiles mass, length, diameter and angle of attack as well as the target's thickness and material properties. If the projectile velocity exceeds the BLV, then the projectile will penetrate the target plate and it will have a residual velocity, $V_{r}$. This can be denoted as

$$
\begin{aligned}
& V_{r}=0,0 \leq V_{s} \leq V_{\ell} \\
& V_{r}=a\left(V_{s}^{P}-V_{\ell}^{P}\right), V_{s}>V_{\ell}
\end{aligned}
$$




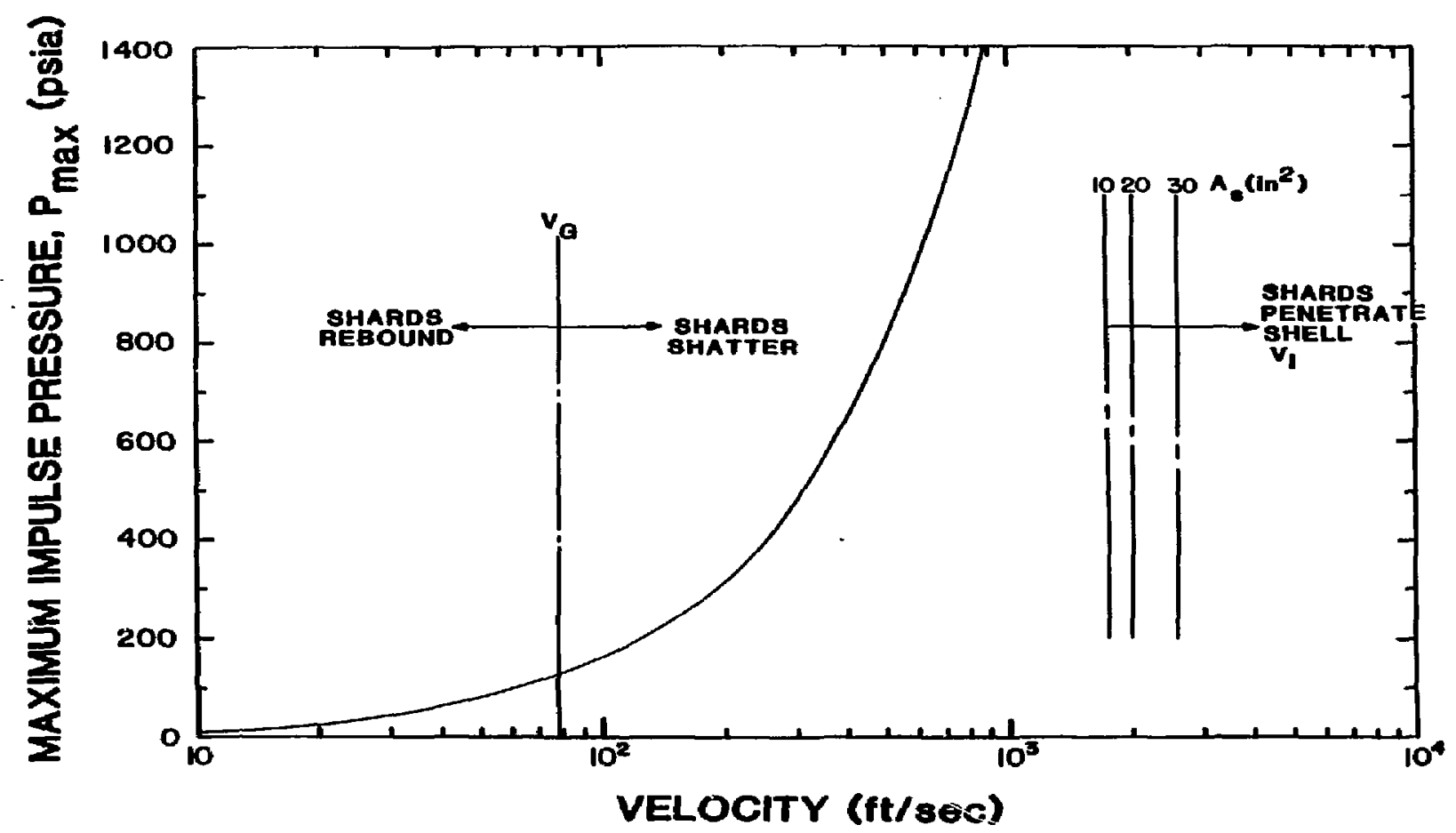

Fig. 9.9 Maximurn inipulse pressure versus graphite shard velocity. 
where

$$
\begin{aligned}
& a=\frac{M}{M+\frac{M T}{3}} \\
& P=2+\frac{2}{3} \\
& M^{\prime}=P_{T} \pi D^{3} \frac{2}{4}
\end{aligned}
$$

and

$$
z=\frac{T}{\delta}(\sec \theta)^{0.75}
$$

where $T$ is the target thickness while $M$ is the mass of the projectile, $D$ its diameter and $\theta$ the angle of attack measured from a line perpendicular to the plate. Letting $L$ be the projectile length, the $B L V, V_{\ell}$, can be calculated using

$$
V_{\ell}=u\left[\frac{L}{D}\right]^{0.15} \sqrt{f(2) \frac{0^{3}}{H}}
$$

where

$$
\begin{aligned}
f(z) & =z+\exp (-z)-1 \\
u & =4000 \text { for rolled homogeneous armor (RHA) } \\
u & =1750 \text { for aluminum. }
\end{aligned}
$$

This formulation holds providing (a) the projectile is a steel rod, (b) $T / D$ is greater than 1.5 and $(\mathrm{c})$ the target material is similar to rolled homogeneous armor or aluminum. Since the projectile is made of graphite, it is likely this formulation will underestinate the BLV. The T/D ratio can be maintained by using an "equivalent" projectile diameter of 0.5 in $(1.27 \mathrm{~cm})$ and length $L$ 
based on the material volume of the shards. The actual graphite pieces will likely be irregularly shaped and impact the shell at random angles. Thus, these estimates of the BLV will be very conservative.

A) though no information was available as to how a graphite panel shatters under a high impulse load, it was assumed that the shards would have areas ranging from 10 to $30 \mathrm{in}^{2}$. Since the thickness of each shard is the same $(21 \mathrm{~cm})$ then the velocity of each will be the same. Figure 9.9 shows the BLV for shards having various areas. It is sufficient to note that the shards cannot attain the penetration velocity even at the highest expected pulse pressure of 1000 psi $(11.03 \mathrm{MPa})$. Thus, it is very unlikely that the missile will penetrate the shell even if they are made of steel. Further, it is likely that the shards will fragment when they impart the shell since the graphite is such a brittle materia?.

If the graphite shard were to strike the glass or quartz optical window in the end of the shell the case is not quite so simple. First, given the angle which the shard must travel to get to the duct window it is not likely that a direct hit by a shard would occur. Secondly, since both the graphite and glass are both brittle, it is not clear whether they would both break an impact or not. Adequate models and data were not found to resolve this issue except in terms of direct impact and the spallation of the glass.

If the graphite impacts the glass at speeds less than about 540 $\mathrm{ft} / \mathrm{sec}(165 \mathrm{~m} / \mathrm{sec})$, then the contact stress (if the shard had a flat face) would be less than the compressive stress of the glass. Thus there would not be any crushing, or indentation of the glass surface. However, the compressive wave set up in the glass would turn into a tensile wave at the free surface and spallation of the glass would occur. Spallation would remove up to one-half of the thickness of the glass as shown in Fig. 9.10(c), but would not penetrate the glass [9.5]. Whether the glass would actually shatter is not likely but would require a more detailed analysis. 


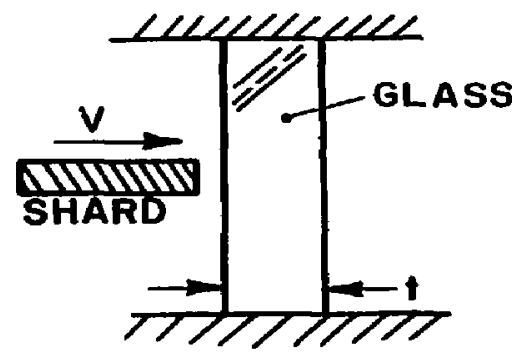

(a)

APPROACH

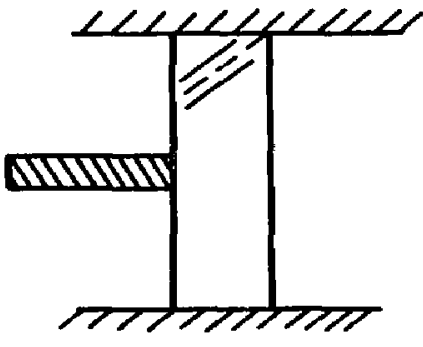

(b)

IMPACT

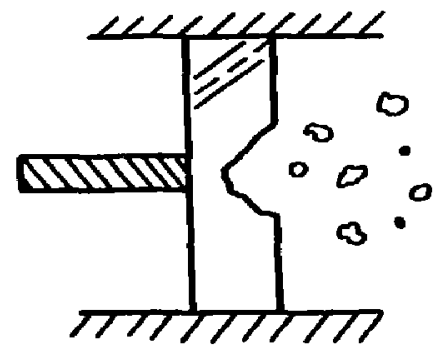

(c)

SPALLATION

Fig. 9.10 Impact of graphite shard on glass port. 


\subsection{Alternative Desion}

A design change contemplated for the SISL process pod would place the Temp-Plate liner on the outside of the shell rather than the inside. This would remove the possibility of a water leak from the liner but also would increase the operating temperature of the tank walls from $70^{\circ} \mathrm{F}\left(21.1^{\circ} \mathrm{C}\right)$ to $400^{\circ} \mathrm{F}\left(204^{\circ} \mathrm{C}\right)$. At this temperature, the yieid stress of $304 \mathrm{~L}$ stainless steel shell decreases 34.2 percent from 35,000 psi (241.1 MPa) to 23,000 psi (158.6 $M P a)$. The elastic modulus, $E$, only decreases from $27.4 \times 10^{6}$ psi $(1.89 \times$ $\left.10^{5} \mathrm{MPa}\right)$ to $26.4 \times 10^{6}\left(1.82 \times 10^{5} \mathrm{MPa}\right)$ while the ultimate strength is $74,000 \mathrm{psi}(510.3 \mathrm{MPa})$ instead of $85,000 \mathrm{psi}(586.2 \mathrm{MPa})$.

The effect of this change on the pod response to a potential watermolten uranium interaction is proportional to the change in the material properties. For example, the allowable design pressures given in Table 9.3 will decrease 34.2 percent, while the maximum strains listed in Table 9.6 will, in general, increase by a factor ranging fram 3.6 to 2.0 times the values given. In both cases there is little added threat to vessel integrity. In the case of dynamic loading, the peak stresses are most affected by the change in the elastic modulus, $E$. Since its value decreases by only 3.6 percent, a similar increase in peak stresses can be expected, Again, the negative effect on system structural response can be expected to be minimal.

In sumary, moving the Temp-plate liner from the inside to the outside of the tank would have a relatively small effect on overall system strustural safety. The shelis' rasistance to missile impact can be expected to be relatively unaffected as well.

\subsection{Conclusions}

Uniform dynamic loads impinging upon the SISL process module pod shell will not plastically deform it under the most likely design basis and once-in-a-lifetime events.

Pressure loadings that may take longer than a minute or two to achieve are not expected to exceed 50 psig. Thus, even if stress levels near 
the end rings are taken into account, under the most conservative assumptions, a factor of safety exists which ranges from about five for the smaller, 9 foot diameter shell, to about three for the 15 foot diameter design.

Missiles generated within the shell due to the water-molten uranium interaction will not damage the vessel. Even under the most conservative assumptions the projectiles will not penetrate the shell. Further, if the projectiles are brittle graphite shards they will likely shatter if their impact velocity exceeds about $79 \mathrm{ft} / \mathrm{sec}(24.1 \mathrm{~m} / \mathrm{sec})$.

Thus, it may be concluded that vapor explosions sccurring within the SISL process module pod will not threaten its integrity even under the most conservative cases.

\subsection{References}

9.1 Eshbach, 0. W. and Souders, M., "Handbook of Engineering Fundamentals, John Wiley \& Sons, New York, Third Edition, 1975, pp. 1326 ff.

9.2 Stackpole Carbon Division, St. Marys, PA 15857, Data Sheet 48-10110M-SCC-10/78.

9.3 Bednar, Henry H., Pressure Vessel Design Handbook, Van Mostrand Reinhold Co., New York, 1981.

9.4 Brush, Don 0. and Almroth, Bo O., Buckling of Bars Plates and Shells, McGraw-Hill Book Co., New York 1975.

9.5 Zukas, J. A., et. al., Impact Dynar.ics, John Wiley \& Sons, New York, 1982. 


\subsection{CONCLUSIONS}

Potential accident initiators and corresponding accident scenarios involving contact between molten uranium metal with cooiant water have been defined to aid in the final process module design in connestion with the SISL. The consequences have been considered in terms of "design basis" accidents (single failures such as a coolant line break), and "once-in-a-lifetime" accident (multiple failures such as simultaneous failures of a coolant line, uranium metal crucible and process module window failure). Consicerations have included both best estimate as well as conservative or bounding calculations of various phenomena including steam explosions and rapid vaporization in connection with various contact modes of molten metal and water and hydrogen formation and combustion potential. Structural considerations have included both mechanical as well as themal attack of the process vessel. The following conclusions have been made:

- The steam explosion potential for design basis accidents is assessed to be very low. The presence of saturated water and high temperature molten metal in the low pressure environment represent a non-explosive system.

- The potential a steam explosion for "once-in-a-lifetime" accident appear higher due to the possibility of subcooled water being available in connection with reaching atmospheric pressure condition in the process vessel. However, the efficiency of such an explosion is assessed to be very low.

- For safety evaluation purposes, a conservative evaluation of the steam explosion potential is adopted. Nevertheless, the calculated dynamic loads impinging upon the process module pod shell will not plastically deform it.

- The oxidation and combustion potencial in conjunction with such postulated steam explosion occurrences is not considered significant. 
- The possible shrapnel production by the postulated steam explosion is insufficient to cause penetration of the vacuum vessel walls and diagnestic port windows.

- Conservative estimates of longer term pressurization events due to coolant vaporization can be accommodated by controlled venting.

- Themal melt-through of the pod she11 due to an initial attack by low temperatur. eutectic formation is considered very unlikely.

In conclusion, a vacuum vessel design based upon nominal operating conditions is sufficient to meet safety requirements in connection with both "design basis" as well as "once-in-a-lifetime" accidents. Controlled venting requirements for removal of steam and hydrogen are specified in order to avoid possible long term pressurization events. Depending upon the resulting accident conditio.i., the racuum system (1.e., the roughing system) could also serve this purpose. Finally, based upon accident evaluations of this study, immedlate shut-off of all ccolant water following an incident leak is not required. In fact, early shut-off of water supply may lead to adverse effects in terms $o$ cuol-down requirements for the melt crucibles etc. These requirements have not been assessed as part of this study. 
APPENDIX A

\section{Sufficient Moiten Material}

To accomplish werk by a steam formation process requires the vaporization of a water mass along a thermodynamic path. Consider a path like that shown in Fig. Al with the initial state being saturated water and the final state saturated steam at a pressure of $0.1 \mathrm{MPa}$. Such a path accounts for the major work producing mechanisms in a vaporization process, i.e., the phase transition and the approximately isothernal expansion down the saturated steam boundary. Since the work involved in raising the pressure for saturated liquid is small, the specific work (W) for a path as shown in Fig. Al would be closely approximated by

$$
w=P_{0} v_{f g o}+P_{0} v_{g o} l n\left(v_{g l} / v_{g o}\right)
$$

In this expression the subscript (0) terms refer to the high pressure vaporization and $v_{g l}$ is the saturated steam specific volume at $0.1 \mathrm{MPa}$. Table Al shows the calculations at several different pressures, and as illustrated for pressures of $5 \mathrm{MPa}$ and above, the specific work is about $1000 \mathrm{~kJ} / \mathrm{kg}$ and the energy required to generate the expansion is approximately $3000 \mathrm{~kJ} / \mathrm{kg}$. As a result, about one-third of the thermal energy transferred could provide mechanical work. 
A 
Table Al

\section{Init1al and Final Pressure $=0.1 \mathrm{MPa}$}

$$
\begin{aligned}
& \text { Vaporization iressure }=1.0 \mathrm{MPa} \\
& \begin{array}{l}
\text { Saturated Liquid }-Q_{1}=763-417=346 \mathrm{~kJ} / \mathrm{kg} \\
\text { Vaporization }-Q_{2}=\mathrm{h}_{\mathrm{fg}}=2015 \mathrm{~kJ} / \mathrm{kg} \\
\text { Saturated Vapor }-Q_{3}=\mathrm{P}_{0}{ }_{\mathrm{gO}} \text { In } \mathrm{v}_{\mathrm{gl}} / \mathrm{v}_{\mathrm{g}}=10^{6}(0.194) \ln (1.7 / 0.19)= \\
425 \mathrm{~kJ} / \mathrm{kg} \\
Q_{\mathrm{I}}=2786 \mathrm{~kJ} / \mathrm{kg}, \mathrm{u}_{\mathrm{fg}}=2089 \mathrm{~kJ} / \mathrm{kg}, w=697 \mathrm{~kJ} / \mathrm{kg}
\end{array}
\end{aligned}
$$

Vaporization Pressure $=5.0 \mathrm{MPa}$

Saturated Liquid $-Q_{1}=1154-417=737 \mathrm{~kJ} / \mathrm{kg}$

Vaporization $-Q_{2}=h_{f_{g}}=1640 \mathrm{~kJ} / \mathrm{kg}$

Saturated vapor $-Q_{3}=P_{0} v_{g o} \ln v_{g 1} / v_{g 0}=5\left(10^{6}\right) 0.039 \ln (1.7 / 0.039)=$ $736 \mathrm{~kJ} / \mathrm{kg}$

$Q_{T}=3113 \mathrm{~kJ} / \mathrm{kg}, u_{f_{g}}=2089 \mathrm{~kJ} / \mathrm{kg}, w=1024 \mathrm{~kJ} / \mathrm{kg}$

Vaporization Pressure $=10.0 \mathrm{MPa}$

Saturated LIquid $-Q_{1}=1408-417=991 \mathrm{~kJ} / \mathrm{kg}$

Vaporization $-Q_{2}=h_{f g}=1317 \mathrm{~kJ} / \mathrm{kg}$

Saturated Vapor $-Q_{3}=P_{0} v_{g 0}$ ln $v_{g 1} / v_{g 0}=10^{7}(0.018) \ln (1.7 / 0.018)=$ $819 \mathrm{~kJ}$

$Q_{T}=3127 \mathrm{~kJ} / \mathrm{kg}, u_{\mathrm{fg}_{g}}=2089 \mathrm{~kJ} / \mathrm{kg}, w=1038 \mathrm{~kJ} / \mathrm{kg}$

Vaporization Pressure $=15,0 \mathrm{MPa}$

Saturated Liquid $=Q_{1}=1611-417=1194 \mathrm{~kJ} / \mathrm{kg}$

Vaporization $-Q_{2}=h_{f g}=1000 \mathrm{~kJ} / \mathrm{kg}$

Saturated Vapor $-Q_{3}=P_{0} v_{g 0}$ In $v_{g 1} / v_{g 0}=1.5\left(10^{7}\right) 0.01$ ln $(1.7 / 0.01)=$ $770 \mathrm{~kJ}$

$Q_{T}=2964 \mathrm{~kJ} / \mathrm{kg}, u_{f_{g}}=2089 \mathrm{~kJ} / \mathrm{kg}, \underline{w}=875 \mathrm{~kJ} / \mathrm{kg}$ 


\section{APPENDIX B \\ Hydrogen Formation from Uranium-Air/Steam Reaction}

Uranium oxidation in both air and steam environments are governed principally by the following physical and chemical rate steps.

Step 1. Diffusion of oxygen and steam molecules towards the oxide surface and counter-diffusion of hydrogen generated away from the surface.

Step 2. Chemical absorption and dissociation of the oxygen and steam molecules into oxygen and hydrogen atoms or ions at the oxide surface.

Step 3. Solid-state diffusion of oxygen in the oxide layer.

Step 4. Chemical combination $\left(U+20+\mathrm{UO}_{2}\right)$ to form oxide at the metal-oxide interface.

It is generally recognized that the rates associated with Steps 2 and 4 are much faster and in subsequent analysis, only the gaseous diffusion and solid-state diffusion are considered in the modelling approach.

Figure B.I depicts a spherical Uranium particle undergoing oxidation in an air-steam mixture. Because of the concentration gradient present near the surface due to self-diffusion and counter-diffusion, a diffusional boundary layer is set up. To describe the rate process, it is convenient to define a mass transfer coefficient such that the rate of diffusion of species $i$ can be expressed as

$$
W_{i}=h_{01}\left(4 \pi x_{0}\right)^{2} \frac{P}{R T}\left(y_{i}-y_{0}\right)
$$

where

$$
\begin{aligned}
& W_{i}=\text { diffusion rate in moles/sec } \\
& h_{D Y}=\text { mass transfer coefficient }
\end{aligned}
$$




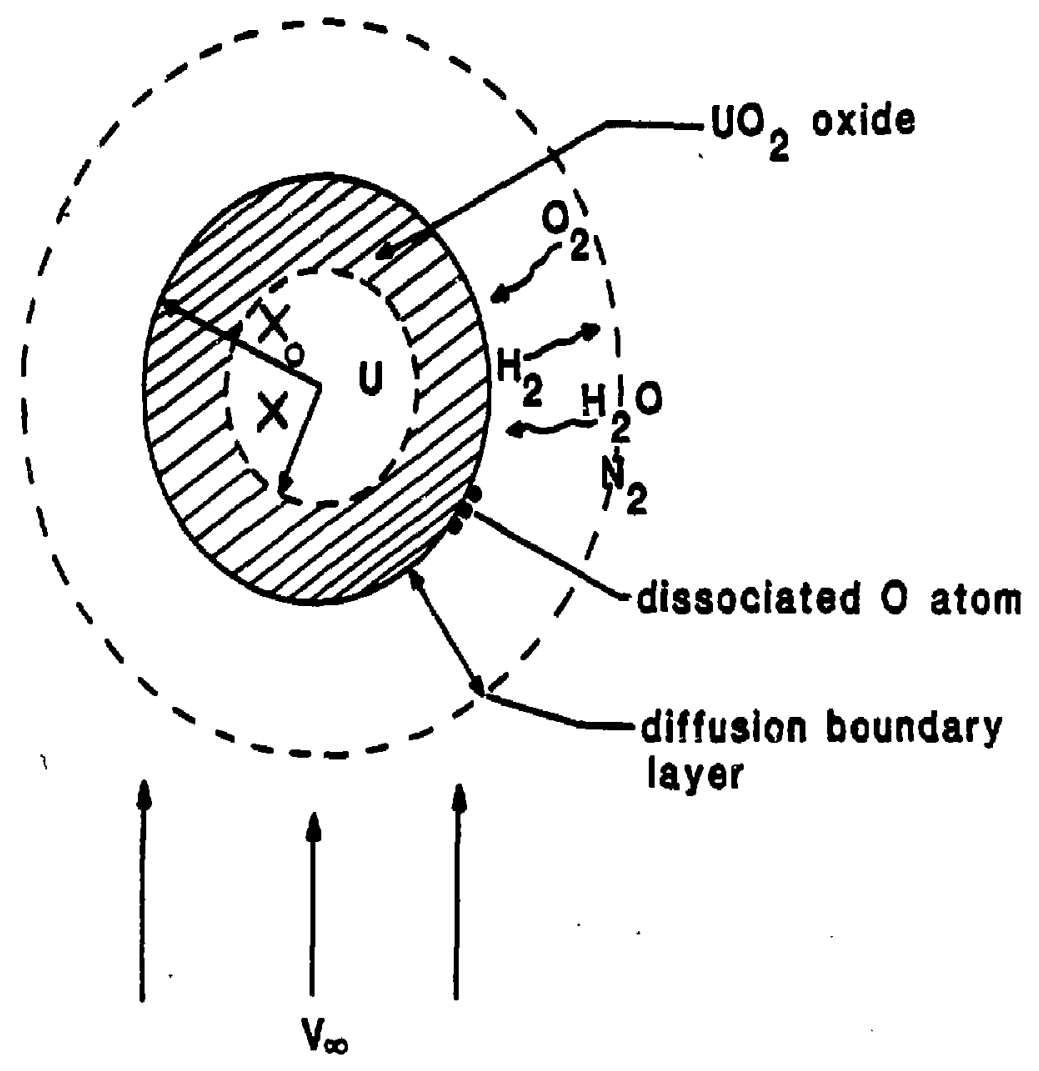

STEAM + AIR

Fig. B.l Pictorial representation of uranium particle undergoing oxidation. 


$$
\begin{aligned}
& y_{i}=\text { bulk mole fraction of component } j \\
& y_{0}=\text { mole fraction of component } i \text { at surface } \\
& x_{0}=\text { radius of particle }
\end{aligned}
$$

Here the mass transfer coefficient can be related to the dimensionless group Sh (which is known as the Sherwood number), and the multicomponent diffusion coefficient $D_{q}$, i.e.,

$$
h_{0 i}=\frac{(S h) D_{i}}{2 x_{0}}
$$

Evaluation of the Sherwood numbs: will be discussed later. To a first approximation, we assume the multicomponent diffusion coefficients to be given by the following binary diffusion coefficients.

(1) Hydrogen - Steam system

$$
0=6.611 \times 10^{-4} \mathrm{~T}^{1.68} / \mathrm{p} \quad \mathrm{m}^{2} / \mathrm{sec}
$$

(2) Oxygen - Nitrogen system

$$
D=1.522 \times 10^{-4} \tau^{1.68} / \mathrm{p} \quad \mathrm{m}^{2} / \mathrm{sec}
$$

From stoichiometry, one can express the oxide growth rate in terms of the diffusion rate,

$$
\frac{d x}{d t}=\frac{1}{4 \pi x^{2}} \frac{M_{m}}{P_{m}}\left(\frac{H_{H_{2} O}}{n_{H_{2} \mathrm{O}}}+\frac{H_{O_{2}}}{n_{O_{2}}}\right)
$$

where

$$
\begin{aligned}
& M_{m}=\text { molecular weight of metal } \\
& P_{m}=\text { density of metal }
\end{aligned}
$$


$n_{i}=$ moles of species $i$ reacted per atom of metal oxidized

Hence

$$
\begin{aligned}
& n_{H_{2} \mathrm{O}}=2 \\
& n_{\mathrm{O}_{2}}=1
\end{aligned}
$$

For the solid state diffusion rate, it is generally found that the diffusion coefficient of oxygen ton in oxide layer obeys the Arrhenius type expression, i.e.,

$$
D_{\left(O_{2} \text {-oxide }\right)} \sim A e^{-\frac{\Delta E}{R T}}
$$

The resulting oxide growth rate is inversely proportional to tine oxide thickness as follows

$$
\frac{d x}{d t}=\frac{A}{2 o_{m}^{2}\left(x_{0}-x\right)} \exp \left(-\frac{\Delta E}{R T}\right)
$$

In an isothermal situation, Eq. B.4 suggests that the oxide layer thickness grows as the square root of time; hence, comonly known as the parabolic rate law. Both values of $A$ and $\triangle E$ are typically determined from isothermal oxidation data. The parabolic rate constant $k_{p}$ (defined as $k_{p}=A \exp (-\Delta E / R T)$ is shown in Fig. B.2 as a function of temperature. Available isothermal data were obtained at temperatures below $1800^{\circ} \mathrm{C}$. Recent study by Baker, et al. $[B .1]$ suggested a higher reaction rate at even higher temperature as depicted by the upper most line in Fig. B.2. Since the temperature of interest in this study is about $2500^{\circ} \mathrm{C}$, the rate constant equation of Baker, et al., should yield an upperbound estimate of the extent of oxidation and hence also of the hydrogen production. This equation is employed in the present study, It should be observed that the parabolic rate constant obtained by Baker was for a uranium-steam system, but it should also apply to the uranium-air (or oxygen) system since the diffusion of the oxygen atom within the oxide layer 'is the controlling step. 


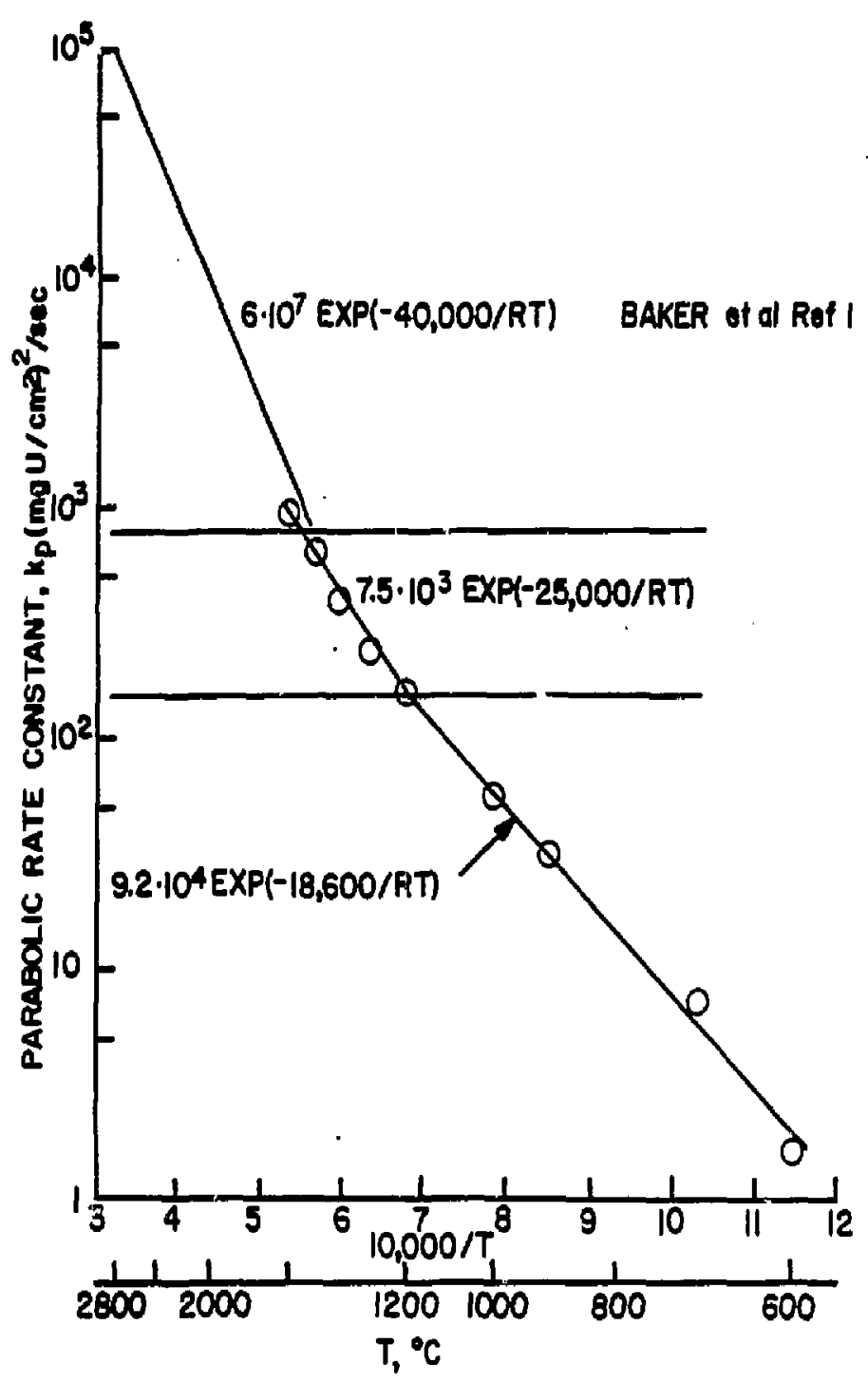

Fig. B.2 Isothermal reaction rate constants for the uranium-steam reaction. 
Initially when a very thin oxide layer is present, the parabolic rate as represented by Eq. $(8,4)$ is much higher than the gaseous diffusion rate, Eq. (B.3) so that the resulting reaction rate would be governed by Eq. (8.3). At some point after a certain thickness of oxide has been formed, the rate would then be limited by the parabolic rate (i.e., solid-state diffusion rate).

In order to calculate the particle's temperature history and percent reaction, an overall energy balance is written around the sphere

$$
\left(\frac{4}{3} \pi x_{0}^{3}\right) \rho_{m} c_{p m} \frac{d T}{d t}=H_{r \times n}-H_{r a d}-H_{c o n y}
$$

where $\mathrm{H}_{\text {rxn }}, \mathrm{H}_{\text {rad }}$ and $\mathrm{H}_{\text {conv }}$ are respectively the heat of reaction, the radiation heat loss and the convective heat loss. These are given by the following expressions.

$$
\begin{aligned}
& H_{r \times n}=p_{m} 4 \pi x^{2}\left(-\frac{d x}{d t}\right)_{\text {rate }}^{\text {limiting }} \\
& H_{r \text { add }}=04 \pi x_{0}^{2}\left(T_{m}^{4}-T_{a m b}{ }^{4}\right) \\
& H_{\text {conv }}=h_{\text {conv }} 4 \pi x_{0}^{2}\left(T_{m}-T_{a m b}\right)
\end{aligned}
$$

Here $\sigma$ is the Stefan-Boitzmann constant and $h_{\text {conv }}$ is the convective heat transfer coefficient. The effective heat of reaction $\dot{q}_{r \times n}$ is the sum of two contributions, that due to steam reaction $\left(q_{r \times n}{ }^{A}=2.5 \times 10^{6} \mathrm{~J} / \mathrm{kg} \mathrm{U}\right)$ and that due to oxygen reaction $\left(q_{\mathrm{rxn}}^{8}=4.6 \times 10^{6} \mathrm{~J} / \mathrm{kg} U\right)$. Thus in general

$$
\bar{q}_{r \times n}=x q_{r \times n}^{A}+(1-x) q_{r \times n}^{B}
$$

where $x$, the fraction due to steam reaction, is obtained as follows. In the regime where gaseous diffusion is the rate controliing step, this fraction is related to the relative diffusion rate, namely 


$$
x=\frac{W_{H_{2} O}}{W_{H_{2}} \mathrm{O}+2 W_{O_{2}}}
$$

On the other hand, in the regime controlled by solid state diffusion, the surface concentrations of steam and oxygen molecules should be proportional to their bulk concentrations since no effective gas diffusional boundary exists. Thus in this situation

$$
x=\frac{Y_{A}}{P_{A}+2 Y_{B}}
$$

where $Y_{A}$ and $Y_{B}$ are the bulk mole fraction of steam and oxygen respectiveTy. For force-convective heat and mass transfer around a sphere, the corresponding correlations are well established [B.2].

$$
\begin{aligned}
& \mathrm{Nu}=\frac{h_{\text {conv }}\left(2 x_{0}\right)}{k}=2.0+0.6 \mathrm{Re}^{1 / 2} \mathrm{pr}_{r} 1 / 3 \\
& S h=\frac{h_{i}\left(2 x_{0}\right)}{D_{i}}=2.0+0.6 \mathrm{Re}^{1 / 2} \mathrm{Sc}
\end{aligned}
$$

Here Nu, Re, $\mathrm{Pr}$, and Sc are the familiar Nusselt number, the Reynolds number, the Prandit number and the Schmidt number respectively.

For many two-component gas mixtures, the ratio $\mathrm{Pr} / \mathrm{Sc}$ has values not far from unity. This ratio cormonly known as the Lewis number is often assumed to be 1 in droplet combustion problems. This assumption is adopted here, thus leading to the obvious statement

$$
\mathrm{Sh}=\mathrm{Nu}
$$

Equation B.5 was integrated using a well-established ordinary differential equation solution package. It is interesting to note that an ignition temperature exists for the Uranium oxidation. As illustrated in Fig. 
B.3, the ignition temperature in a steam atmosphere is about $1500^{\circ} \mathrm{C}$ and is about the same in air. It is also important to note that the extent of oxidation is a strong function of particle size and is essentially independent of the initial metal temperature as long as this temperature is above the ignition temperature.

Figures $B, 4$ and $B, 5$ sumarize the percent oxidation as weil as the amount of hydrogen generation as a function of particle size. As expected, the smaller the particle, the greater is the percent oxidation. For example, the percent reaction is about $50 \%$ for a $1 \mathrm{~mm}$ particle whereas this value drops to $5 \%$ for a $10 \mathrm{~mm}$ particle. In general, the percent oxidation is rather insensitive to the air-steam mixture composition. On the other hand, the amount of hydrogen generated is influenced by the composition. But again, the dependence on particle size is clearly demonstrated. In both figures, the results are based on a free-stream air-steam velocity of $10 \mathrm{~m} / \mathrm{sec}$. A $50 \%$ perturbation on this velocity only changes the percent oxidation by less than 10\% for a 100 micron particle, and this sensitivity is even less for larger particles.

\section{B. 1 References}

B.1 L. Baker, M. Epstein, H. K. Fauske, R. E. Henry and J. C. Leung, "Hydrogen Evolution during LWR Core Damage Accidents," in Proc. Thermal Nuclear Reactor Safety Meeting, Chicago (Aug. 1982).

B.2 R. B. Bird, W. E. Stewart and E. N. Lightfoot, Transport Phenomena, John Wiley \& Sons, p. 647 (1960). 


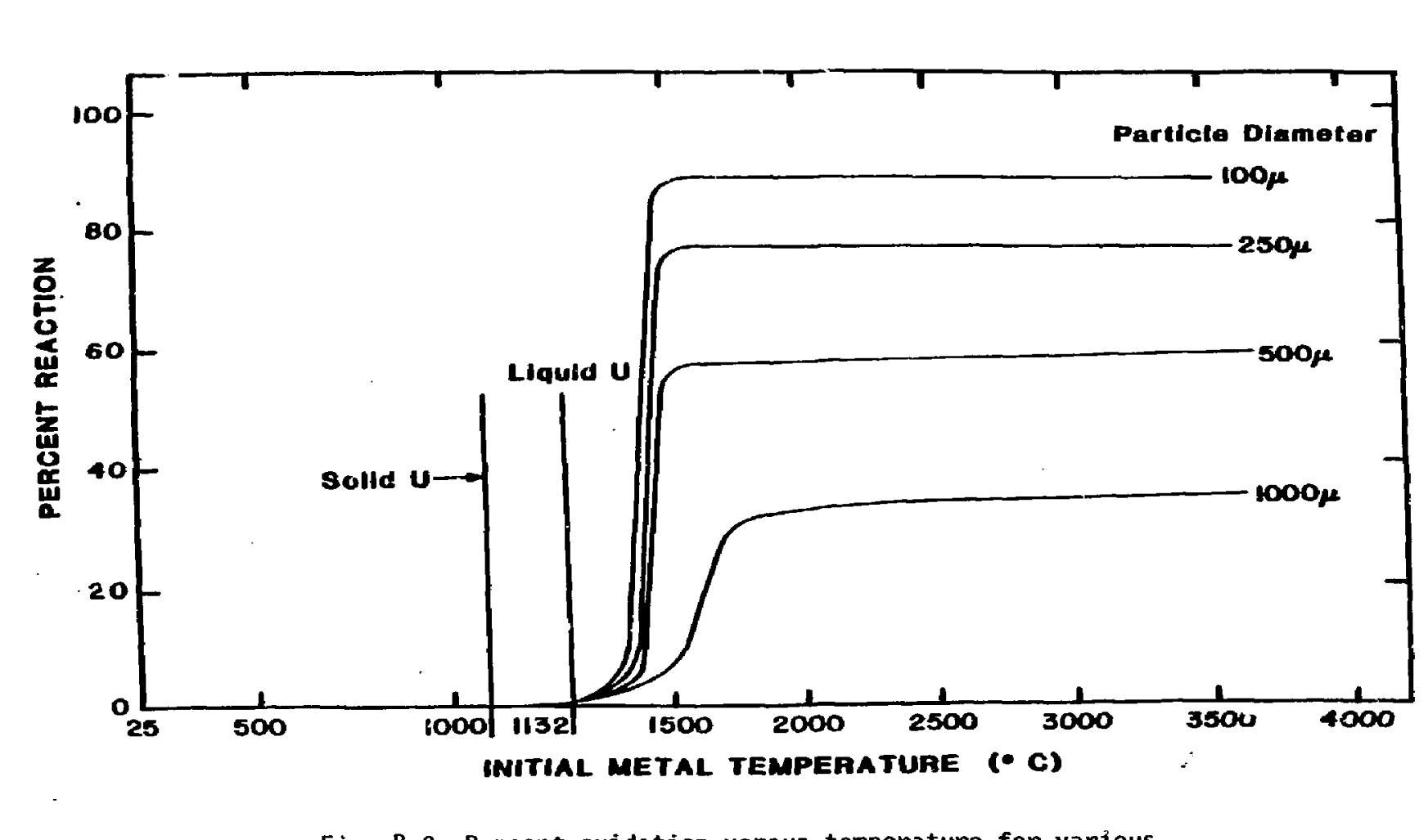




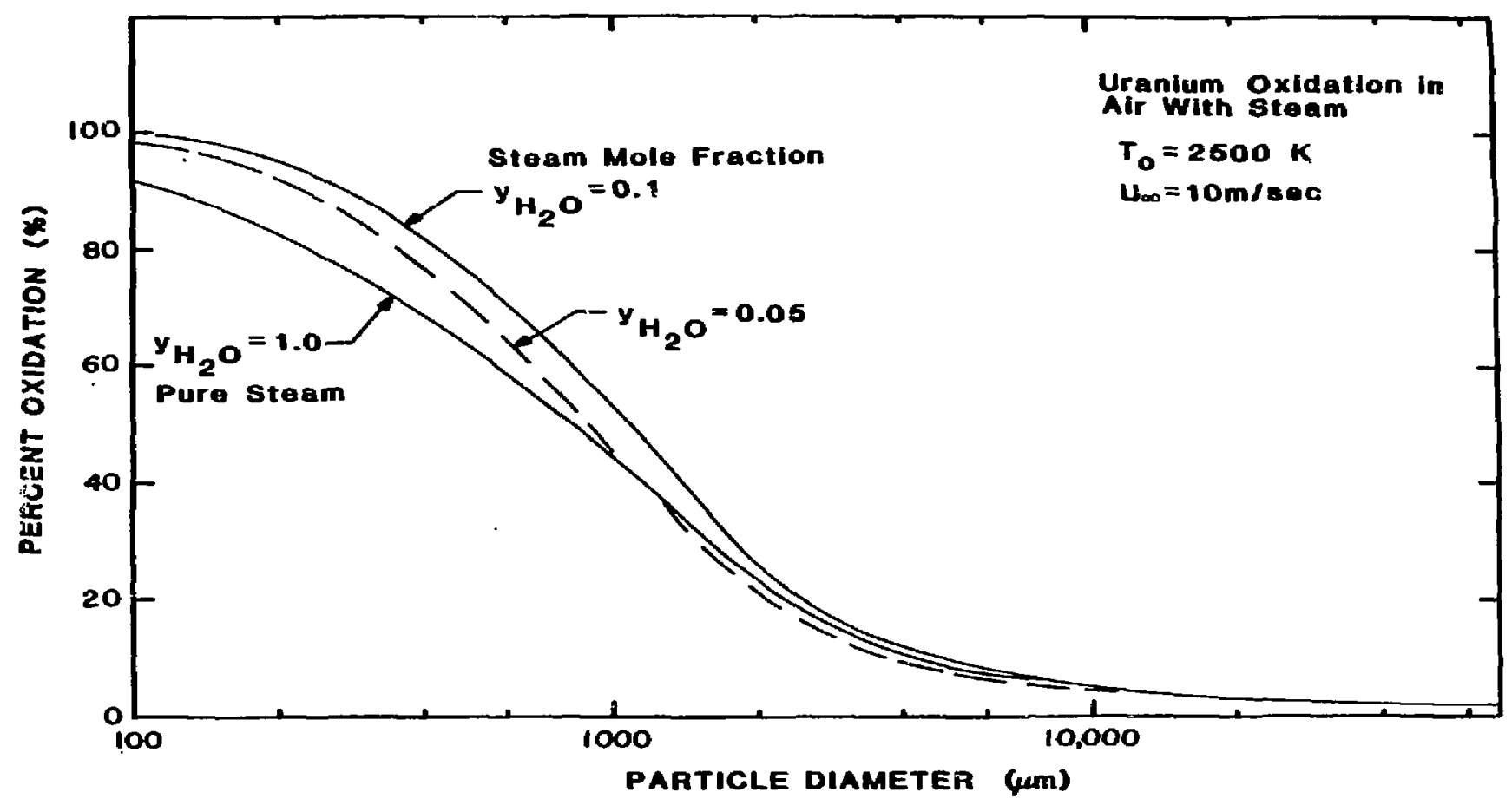

Fig. B.t Percent reaction versus particle size for various steam concentrations. 


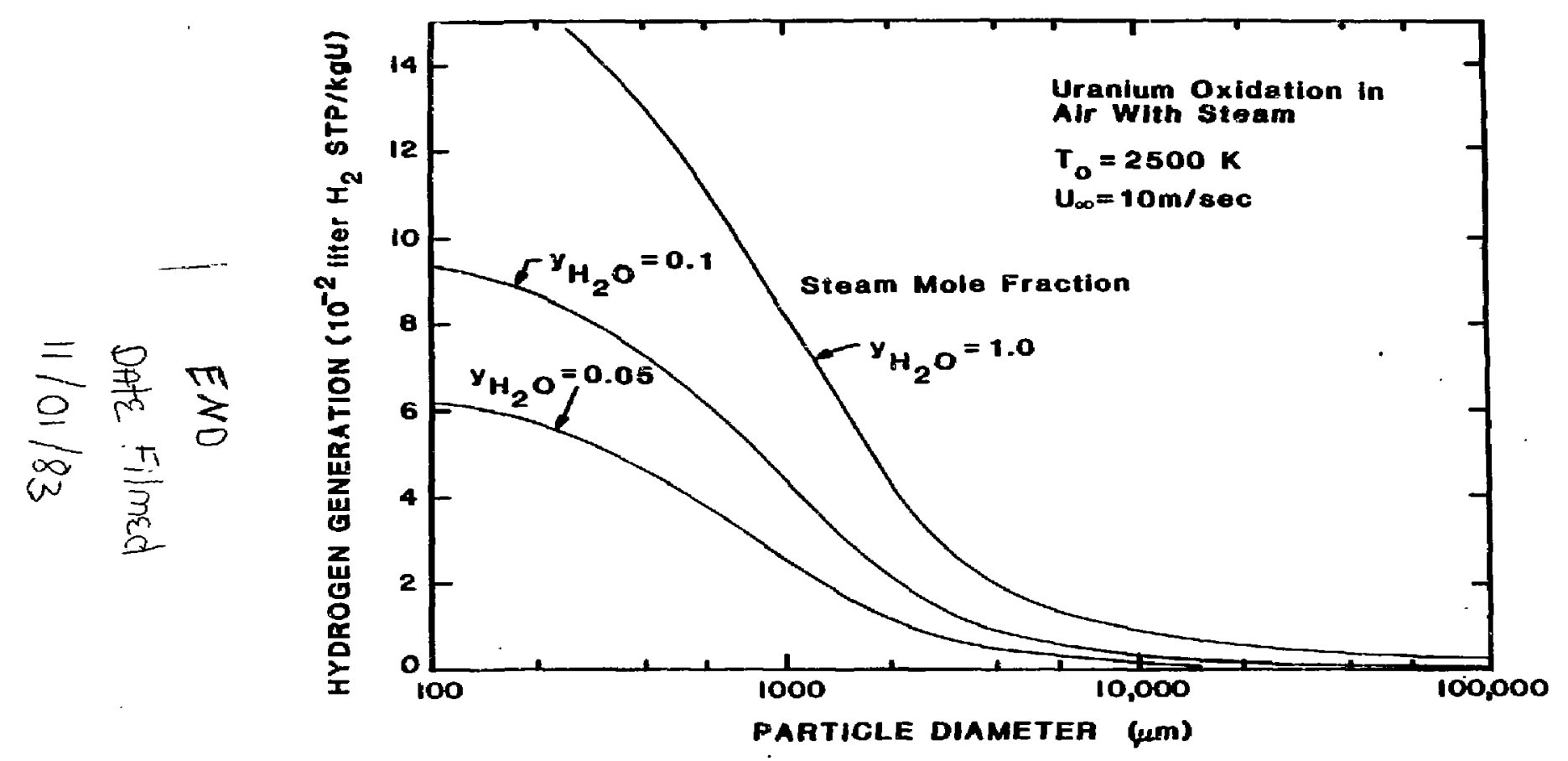

Fig. B.5 Hydrogen evolution versus particle size for various steam concentrations. 